\title{
Review Article \\ Trachoma and Ocular Chlamydial Infection in the Era of Genomics
}

\author{
Tamsyn Derrick, Chrissy h. Roberts, Anna R. Last, Sarah E. Burr, and Martin J. Holland \\ Department of Clinical Research, Faculty of Infectious Tropical Diseases, London School of Hygiene and Tropical Medicine, \\ London WCIE 7HT, UK
}

Correspondence should be addressed to Tamsyn Derrick; tamsyn.derrick@lshtm.ac.uk

Received 17 April 2015; Accepted 5 August 2015

Academic Editor: Amedeo Amedei

Copyright (C) 2015 Tamsyn Derrick et al. This is an open access article distributed under the Creative Commons Attribution License, which permits unrestricted use, distribution, and reproduction in any medium, provided the original work is properly cited.

\begin{abstract}
Trachoma is a blinding disease usually caused by infection with Chlamydia trachomatis (Ct) serovars A, B, and C in the upper tarsal conjunctiva. Individuals in endemic regions are repeatedly infected with $C t$ throughout childhood. A proportion of individuals experience prolonged or severe inflammatory episodes that are known to be significant risk factors for ocular scarring in later life. Continued scarring often leads to trichiasis and in-turning of the eyelashes, which causes pain and can eventually cause blindness. The mechanisms driving the chronic immunopathology in the conjunctiva, which largely progresses in the absence of detectable $C t$ infection in adults, are likely to be multifactorial. Socioeconomic status, education, and behavior have been identified as contributing to the risk of scarring and inflammation. We focus on the contribution of host and pathogen genetic variation, bacterial ecology of the conjunctiva, and host epigenetic imprinting including small RNA regulation by both host and pathogen in the development of ocular pathology. Each of these factors or processes contributes to pathogenic outcomes in other inflammatory diseases and we outline their potential role in trachoma.
\end{abstract}

\section{Introduction}

Sightsavers International estimates that every 15 minutes a person loses sight as a result of trachoma [1]. As such, trachoma remains the world's leading infectious cause of blindness despite significant efforts to control and eliminate the disease [2]. Trachoma is currently considered endemic in 51 countries worldwide and only seven formerly endemic countries have reached target elimination thresholds [2]. The Alliance for the Global Elimination of Blinding Trachoma has set the goal of 2020 for the elimination of trachoma. The aim is to control trachoma through the implementation of surgery for trichiasis, antibiotics to treat infection, facial cleanliness, and environmental improvements to reduce transmission (SAFE). Currently 31 trachoma endemic countries implement SAFE, which is effective in controlling trachoma if well conducted. Azithromycin is the antibiotic of choice used in mass drug administration (MDA) programmes for trachoma control. There are additional beneficial effects of azithromycin MDA, including reduced all-cause mortality [3] and potential to reduce clinical disease through its anti-inflammatory properties [4]. There remains a need to pursue vaccine development as there are circumstances when SAFE is poorly effective and there is uncertainty about its universal application. The lack of randomized controlled trials examining the effectiveness of the $\mathrm{F}$ and $\mathrm{E}$ components for the interruption of transmission, alongside the historical lack of molecular laboratory tools able to identify transmission events, raises questions on the basic understanding of their effectiveness. Additional concerns with the A component include the long-term use of antibiotics in populations where MDA has failed to control disease [5], introduction of resistance in other bacterial species [6], and the continued progression of scarring and trichiasis in populations where MDA has been implemented [7]. It is also not currently understood whether effective mass treatment leads to arrested immunity and it is unclear what impact the elimination of ocular chlamydial exposure in childhood might exert later in adolescent and adult urogenital disease. Chlamydiae can reside in the gastrointestinal tract in the absence of clinical disease and this has led to the suggestion that azithromycin treatment failures (at least in urogenital disease) may be because gastrointestinal 
Chlamydiae are refractory to azithromycin treatment and can act as a source for autoinoculation $[8,9]$. A vaccine offering effective long-term protection against disease in both ocular and urogenital chlamydial disease therefore remains desirable.

Trachoma is initiated by infection of the tarsal conjunctiva with the intracellular bacteria Chlamydia trachomatis $(C t)$. There are a number of classification systems for the clinical signs of trachoma. Under the WHO simplified grading system, the presence of five or more follicles on the conjunctival surface is classified as trachomatous inflammation follicular (TF). Ct infection is independently associated with TF $(\mathrm{OR}=11.2$ (95\% CI 6.9-18.1) [10]), although this value varies between populations depending on disease sign prevalence and becomes disassociated from TF once prevalence is low. Repeated $C t$ infection in endemic communities can trigger chronic conjunctival inflammation (trachomatous inflammation intense, TI) in some individuals, causing conjunctival fibrosis (trachomatous scarring, TS). Progressive fibrosis may lead to entropion, inward turning, or misdirected lashes (trachomatous trichiasis, TT), all of which abrade the corneal surface. This abrasive damage may lead to corneal opacity (CO) and blindness. Figure 1 shows reflective in vivo confocal microscopy scans, histology sections, and photographs of the tarsal conjunctiva that illustrate the changes in tissue architecture that occur in the different stages of trachomatous disease.

The human trachoma vaccine trials that took place in the 1960s concluded that some short-term strain-specific protection from infection was induced, amidst concerns that pathology was exacerbated in some cases, supported by data from monkey models [13]. The data from these large placebocontrolled trials has been recently reinterpreted in the context of current grading systems and our current knowledge of disease pathogenesis. Only trial III in The Gambia recorded evidence of conjunctival scarring. Two doses of prophylactic vaccination made from two live strains in mineral oil were given three weeks apart to children aged $0-4$ years. There was no protection from active trachoma; however the vaccinated group had a reduced prevalence of scarring disease two years later [14]. When all three Gambian trials are reviewed in the context of what is now known about disease pathogenesis, vaccine-induced exacerbation of disease may not be a significant concern, raising hopes that current vaccine formulations may be successful $[15,16]$.

\section{Immunopathology of Trachoma}

Despite extensive research, the mechanistic link between chronic inflammation and progressive scarring remains elusive [7]. The scarring observed in both trachoma and urogenital disease is thought to be a result of the host response to infection rather than a direct effect of the bacteria. Defining the features of protective versus pathogenic immunological responses in chlamydial disease (reviewed in [17]) is crucial to the understanding of disease and for efficacious vaccine design.

Currently, two models have been put forward to explain the immunopathogenesis of chlamydial disease: the immunological and cellular paradigms. The traditional immunological paradigm implicates the adaptive immune system.
Initial studies on chlamydial infection found that repeated infection exacerbated inflammation and that inflammatory pathology continued in the absence of $C t$. At first, a delayed type hypersensitivity (DTH) reaction triggered by a chlamydial antigen was hypothesized. The chlamydial heat shock protein 60 (HSP60) was considered a candidate antigen to trigger DTH but was not found to exacerbate pathology when tested in a guinea-pig model [18]. Antibodies to HSP60 predicted a 2-3-fold higher risk of $C t$ pelvic inflammatory disease (PID) in humans and higher levels of antibodies specific to HSP60 were found in women with the most severe forms of urogenital disease [19]. Likewise antibodies to HSP60 were associated with tubal factor infertility (TFI) and inflammatory trachoma $[20,21]$; however it remains unclear whether these antibodies cause pathology or are a result of a greater number or more severe episodes of infection. More recent screening of sera from trichiasis patients and controls detected differential patterns of antibody recognition for a number of $C t$ antigens; however HSP60 responses were not significantly different [22].

Previous research demonstrated that individuals with scarring trachoma had Th2 patterns of cytokine expression [23], whereas those with strong Th1 responses efficiently cleared infection [24]. This opposed the DTH theory and suggested that a Th2 response either was ineffectual at clearing infection or led to enhanced pathology and that CD4+ Th1 IFN $\gamma$ responses were a key element of protective immunity in trachoma. Both CD8+ and CD4+ T cell infiltrates are associated with the conjunctival follicles that are characteristic of TF; however CD4+ T cells are thought to outnumber CD8+ [25]. NK cells have more recently been identified as a major early source of IFN $\gamma$ in response to $C t$ [26]. Despite the primary function of CD8+ T cells in defense against intracellular pathogens, data from murine models previously found a limited role for $\mathrm{CD} 8+\mathrm{T}$ cells in anti-Ct immunity [27]. Recent evidence in the macaque model of trachoma challenges this theory and suggests that depletion of CD8+ T cells can abrogate protective immunity [28]. Characterization of the roles of each of these cell types in chronic scarring trachoma has proved difficult to address, however, largely due to the natural history of scarring disease.

Stephens suggested an alternative model of disease [29] in which epithelial cells at the infection site play a central role as mediators of the innate immune response. Epithelial cells infected with $C t$ secrete a number of proinflammatory cytokines and growth factors, such as IL-8, GRO $\alpha$, IL- $1 \alpha$, IL-6, and granulocyte-macrophage colony-stimulating factor (GM-CSF). The secretion of these cytokines is delayed compared to the kinetics of secretion upon infection with other invasive bacteria and persists throughout the 2-4-day developmental cycle of Ct. The secretion of IL-1 $\alpha$ by infected cells was shown to upregulate proinflammatory cytokine production by neighboring uninfected cells, promoting a strong inflammatory response [30]. Lymphocytes of the adaptive immune system are attracted to the infection site by the chemotactic gradient and subsequent infections include memory populations that amplify the response. $C t$ infected cells also secreted the profibrotic cytokine IL-11, a member of the IL-6 family [31, 32]. Recent evidence from a primary-like 


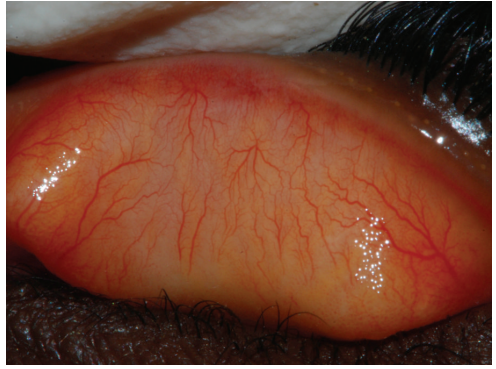

(a)

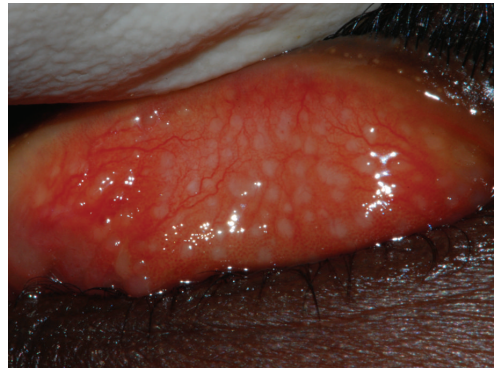

(e)

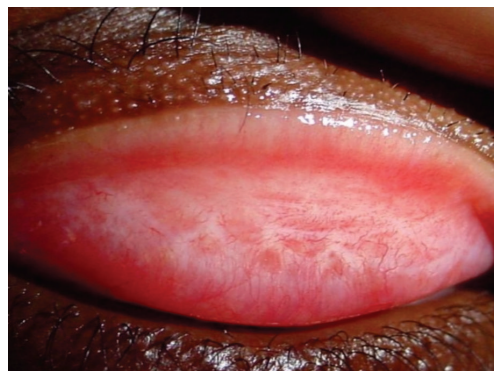

(i)

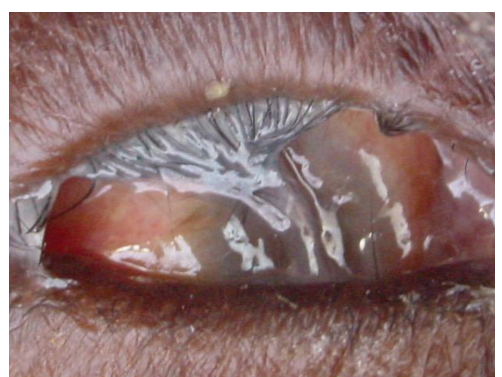

(m)

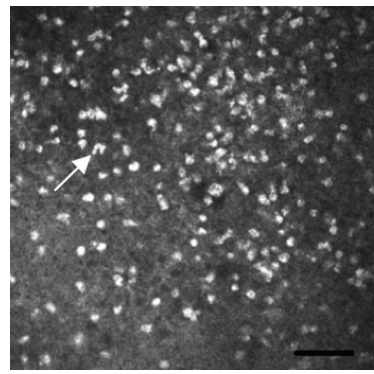

(b)

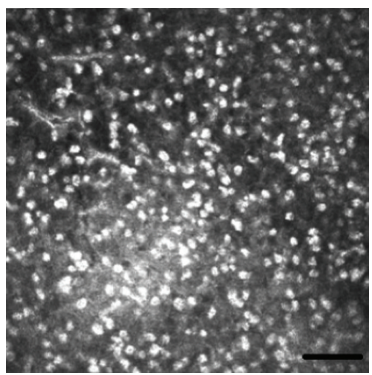

(f)



(j)



(n)

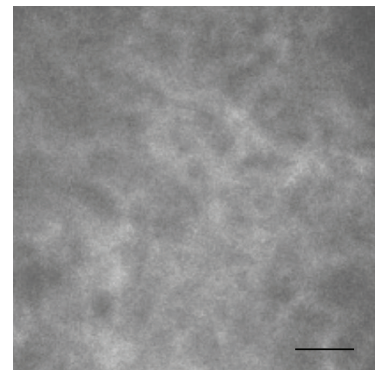

(c)

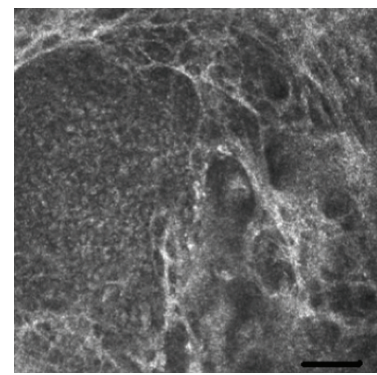

(g)



(k)

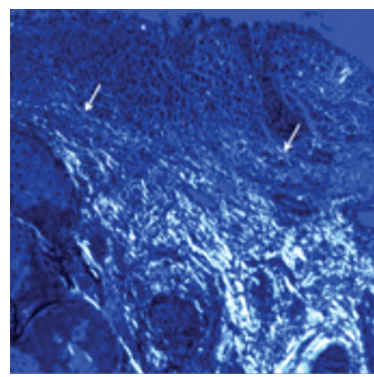

(o)

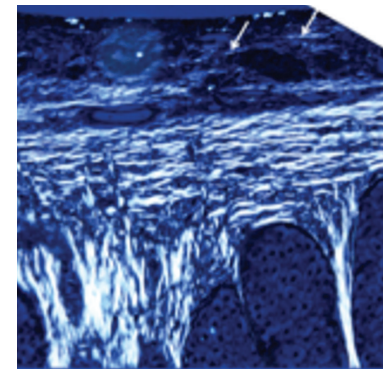

(d)

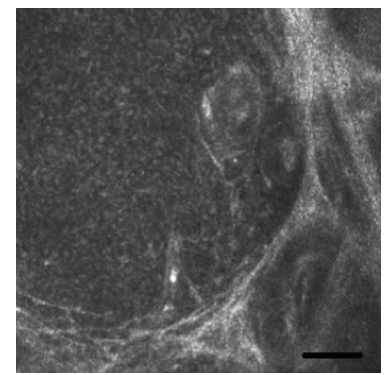

(h)

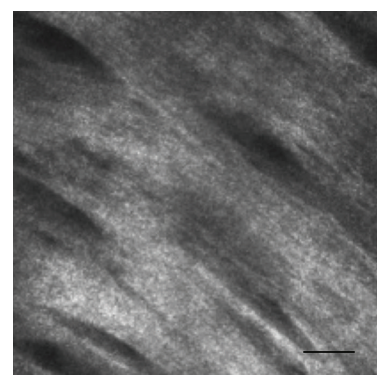

(l)

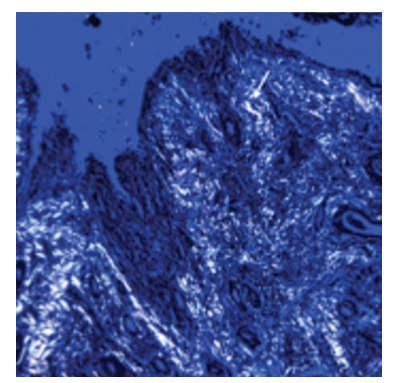

(p)

FIGURE 1: Images from a normal healthy eye $(\mathrm{a}-\mathrm{d})$ and from individuals with follicular trachoma (e-h), trachomatous scarring (i-l), and trichiasis and progressive scarring $(\mathrm{m}-\mathrm{p})$. (a), (e), (i), and $(\mathrm{m})$ are photographs of the tarsal conjunctiva showing normal appearance (a), papillary inflammation and follicles (e), bands of trachomatous scarring (i), and extreme trichiasis and corneal opacity (m). (b), (c), (f), (g), (h), (j), (k), and (l) are in vivo confocal microscopy images of the tarsal conjunctiva at various depths (the bar represents $50 \mu \mathrm{m}$ ). A moderate number of inflammatory nuclei are present in the subepithelium of a healthy eye (b), whereas a higher number are present in trachomatous inflammation (f). Follicles can be seen in ( $\mathrm{g}$ ) and (h). The connective tissue of the healthy conjunctiva is amorphous (c), whereas successive grades of trachomatous scarring are seen as a heterogeneous clumpy appearance (j), defined tissue bands that make up $<50 \%$ of the scan area $(\mathrm{k})$, and defined bands that make up $>50 \%$ of the scan area (l). (d) and (n-p) are histological images of tissue scarring using polarized light (original magnification $\times 100$ ). In the healthy conjunctiva, collagen fibers are parallel (arrows) with the surface epithelium (d), whereas progressive disorganization of this appearance is observed in scarring $(n-p)$. Images are kindly provided with permission from Matthew Burton and Victor Hu and are adapted from Hu et al. 2011 [11] and Hu et al. 2013 [12]. 
polarized epithelial cell model showed that IL-11 was secreted preferentially from the basolateral membrane and IL1ra from the apical membrane in Ct infected cells [33]. The $\mathrm{T}$ cell chemokines RANTES and IP10 were also downregulated in productively $C t$ infected cells, suggesting that $C t$ attempts to avoid stimulation of the immune response in order to maintain its intracellular niche, potentially leading to longer infections and chronic pathology [33]. Recent genome-wide scale array studies from clinical samples support Stephens's hypothesis. Expression profiling of children in The Gambia with active trachoma versus healthy controls revealed a strong upregulation of the innate immune response [34]. Along with the expected infiltration of neutrophils, lymphocytes, and the inflammatory cytokine pathways consistent with histopathology [35], the natural killer (NK) cell response was also enhanced. A transcriptome study conducted in Ethiopian adults with either trachomatous trichiasis (TT) or TT with inflammation (TTI) versus healthy controls found that despite less than $1 \% C t$ infection prevalence, markers of ongoing subclinical inflammation and tissue remodeling were evident in the TT group and were more pronounced in the TTI group [36]. These markers were consistent with an activated and proinflammatory epithelium. There was a lack of evidence for a profibrotic Th2 response and a very limited Th1 response. Subsequent targeted quantitative-PCR studies have reemphasized the role of the innate immune response in trachoma in both children and adults $[37,38]$. These studies found antimicrobial peptides psoriasin (S100A7), DEFb4A, and SAA1, inflammatory cytokines $I L 17, I L 1 \beta$, and TNF, inflammatory chemokines (CCL18 and CXCL5), MMPS, and CTGF were upregulated in trachomatous disease. Increased IL17 expression was highlighted as characteristic of active trachoma and is thought to coordinate the proinflammatory response [37].

Overall these studies suggest that clearance of $C t$ infection requires an appropriate acute Thl response with IFN $\gamma$ and CD8+ $\mathrm{T}$ cells. They also support the case for the central role of epithelial cells in ongoing trachomatous inflammation and pathogenesis that leads to TT. This would imply that neither the cellular nor the immunological paradigm can fully explain disease but that active cross talk between cellular (innate epithelial cell responses) and immunological (adaptive immunity) systems is required.

\section{Host Genetic Association Studies and Trachoma}

The assumed link between immune driven inflammation and conjunctival scarring and its blinding sequelae led to the first genetic association studies which focused on immune response genes. Immune response genes located within the Major Histocompatibility Complex (MHC) drive the adaptive cellular response and initial studies focused on the association of trachomatous scarring disease with alleles in HLA class I and class II loci. The intracellular nature of chlamydial infection suggested that class I restricted CD8+ $\mathrm{T}$ cell responses would be important in controlling infection and that these might be related to later scarring disease. MHC class II loci would be expected to contribute by defining the profile of anti-Ct antibody responses and cytokines via CD4+ class II restricted T cells.
The first reported genetic association study in trachoma in Gambians [39] found evidence that a specific HLA class I serological determinant of the HLA-A2 supertype (HLAA28) was associated with scarring trachoma $(\mathrm{OR}=1.88$, $P=0.046)$ and observed that approximately $26 \%$ of scarring cases had HLA-A28, compared to $16 \%$ of controls. HLA-A28 is made up of at least 3 molecular subtypes (HLA-A* 68:01, HLA-A* 68:02, and HLA-A*69:01), of which HLA-A*68:02 was thought to be the most frequent allele in Gambians. In a subset analysis of a limited number of samples from the same study, molecular typing showed that the HLA-A* 68:02 allele was strongly associated with scarring trachoma $(\mathrm{OR}=$ 3.14, CI 1.32-7.44, and $P=0.009$ ). No alleles of either of the MHC class II genes, HLA-DRB1 or HLA-DQB1, were found to be associated with scarring. Antibody responses to chlamydial HSP60 were positively correlated with the allele HLA$\mathrm{DRB1}^{*}$ 07:01 ( $\left.\mathrm{OR}=2.6, P=0.02\right)$ and negatively correlated with both HLA-DQB1*03:01 $(\mathrm{OR}=0.42, P<0.001)$ and HLA-DQB1 ${ }^{*} 05: 01$ (OR $\left.=0.55, P=0.046\right)$ [40]. Later studies also linked HLA class II alleles to anti-Ct antibody prevalence and quantity in the clinical context of sexually transmitted Ct infections [41, 42].

It had previously been shown that synthetic peptides based on chlamydial sequences (MOMP and HSP60) could elicit $H L A-B 8$ and $H L A-B 35$ restricted CD8+ CTL responses in peripheral blood of individuals from trachoma endemic regions [43]. In an attempt to link the observed $H L A-A^{*}$ 68:02 association to an effector mechanism, a follow-up study [44] investigated whether $H L A-A^{*}$ 68:02 restricted CD8+ CTLs or IFN $\gamma$ producing cells were associated with $C t$ specific immune responses in a small number of scarring cases and disease-free controls. Peptides from 3 chlamydial antigens that were predicted to bind HLA-A*68:02 were used to stimulate cells but no chlamydia-peptide specific responses were detected. This led the authors to suggest either that the peptides that were chosen did not represent natural epitopes or that $H L A-A^{*}$ 68:02 restricted CD8+ T cells were not important mediators in ocular disease. An alternative experimental approach and one that did not require in vitro restimulation used HLA-A2-MOMP tetramers and found that increased frequencies of CD8+ tetramer positive cells were coincident with current ocular $C t$ infection and longer durations of infection [45]. Effector functions of these cells were not investigated but it was noted that the tetramers used to identify cells also bound to the TCR of HLA-A28 restricted $\mathrm{T}$ cells. This supported a model under which the HLA-A* 68:02 allele might contribute to scarring disease via prolonged or chronic ocular infections.

Outside of trachoma, antichlamydial CD8+ MHC class I restricted cells have been clearly demonstrated in murine models [46] and in humans exposed to urogenital infections [47]. Recently there has been a resurgence of interest in the importance of CD8+ MHC class I restricted T cells, following work in a murine model of urogenital disease [48] and in vaccinated monkeys [49]. Following vaccination with the plasmid-free attenuated strain of $C t$, monkeys with a common MHC class II haplotype (M1) were protected from virulent ocular challenge. Subsequent work found that protection was mediated through CD8+ $\mathrm{T}$ cell recognition of soluble 
chlamydial antigens [28] and not through class II restricted CD4+ T cells. Most recently, an immune-proteomic screening approach in mice showed that only a small percentage $(\sim 3 \%)$ of the $C t$ proteome is processed for presentation by $\mathrm{MHC}$ class II molecules. Ct proteins that were processed were the expected immunodominant proteins such as MOMP, PmpE, PmpF, and PmpG and were presented on a wide range of I-A and I-E MHC haplotypes [50]. The immunogenicity of these proteins was also subject to both MHC class II selection and chlamydial peptide sequence diversity. Overall, this suggests that studies of sufficient size and power to account for the high degree of polymorphism and small effect size are required to further investigate HLA class II disease susceptibility. Overall, reports of associations between human MHC polymorphisms and chlamydial infection and disease have been inconsistent and have not identified a specific causal pathway. Collectively these studies do suggest an important but complex role for the MHC in chlamydial host resistance and disease.

Following the early MHC class I and class II genetic association studies in Gambians, a trachoma-HLA association study was conducted in Omanis using a serologically based typing system. This found some evidence of association between TT and the HLA class II DR16 and DR53 antigens [51]. Further studies in Tanzanians [52] found that trichiasis was less common in women carrying $H L A-D R B 1^{*} 11$ alleles (OR $=0.48$, CI $0.26-0.90$, and $P=0.02)$ and more common in those carrying $H L A-B^{*} 07$ (OR $=3.26$, CI $1.42-7.49$, and $P=0.004)$ or $H L A-B^{*} 08(\mathrm{OR}=5.12$, CI $1.74-15.05$, and $P=0.001)$. More recently, a much larger study in Gambian families also highlighted the association between HLA$B^{*}$ 08:01 alleles and scarring [53], but analysis based on current knowledge of the HLA system would suggest that HLA$\mathrm{B}^{*}$ 08:01 could be a proxy marker for the HLA-C epitope of the Killer Cell Immunoglobulin-like Receptors (KIRs). This epitope is defined by a dichotomous amino acid polymorphism at position 80 of the HLA-C heavy chain [54]. HLA-C alleles carry $\mathrm{Asn}^{80}$ and are designated $\mathrm{C} 1$ whilst those with Lys $^{80}$ are C2. The HLA-C KIR epitope determines which KIR can bind the ligand, with KIR2DL1 binding to HLAC2 and both KIR2DL2 and KIR2DL3 binding to HLA-C1 [55-57]. KIR are a polymorphic family of membrane-bound immune-receptors found on natural killer (NK) cells [58-60], where they are usually considered to control the licensing $[61]$ and responsiveness $[62,63]$ of the NK cytotoxic immune response. KIRs are also present on NK-T cells and T cells [64, 65], though the functional contribution of KIRs to T cell reactivity is relatively less well studied $[66,67]$. The finding that HLA-C2 was a significant predictor [53] of increased risk of scarring in Gambian families $\left(\mathrm{OR}_{\mathrm{C} 1 / \mathrm{C} 2}=2.29, P_{\mathrm{C} 1 / \mathrm{C} 2}=\right.$ $\left.0.0061 \mid \mathrm{OR}_{\mathrm{C} 2 / \mathrm{C} 2}=3.97, P_{\mathrm{C} 2 / \mathrm{C} 2}=0.0004\right)$ further suggested a role for NK cells in trachomatous scarring. Epistatic effects were observed since KIR (Chromosome 19) genotype modified the risk of scarring depending on HLA-C (Chromosome 6) genotype; HLA-C2 showed additive gene dosage effects and individuals carrying both KIR2DL2 and KIR2DL3 had the highest relative risk $\left(\mathrm{OR}_{\mathrm{C} 1 / \mathrm{C} 2}=2.33, P_{\mathrm{C} 1 / \mathrm{C} 2}=0.1\right.$ । $\left.\mathrm{OR}_{\mathrm{C} 2 / \mathrm{C} 2}=5.95, P_{\mathrm{C} 2 / \mathrm{C} 2}=0.0025\right)$. NK cells are likely to be important in the initial host response to ocular challenge, since it has been shown that they are the main cellular source of IFN $\gamma$ in response to in vitro elementary body stimulation [26]. There was no evidence in the study of scarring trachoma in Gambian families that the previously identified HLA$A^{*}$ 68:02 allele was associated with early scarring $(P=0.27)$.

MHC class I and class II association studies were also extended into class III loci. A polymorphism in the tumour necrosis factor (TNF) promoter region was found to associate with scarring under an additive model $\left(\mathrm{OR}_{\mathrm{A} / \mathrm{G}}=1.59\right.$, $\mathrm{OR}_{\mathrm{A} / \mathrm{A}}=3.4$, and $P=0.03$ ) [68]. Whilst scarring disease was also associated with increased detection of TNF protein in tear fluid $\left(\mathrm{OR}_{\mathrm{add}}=2.5, P=0.013\right)$, TNF levels in the tear fluid did not associate with the genotypes of the TNF-308 polymorphism. A later study of trichiasis patients and controls found an association between TNF-308A and disease, which was significant under a dominant, rather than additive, genetic model $\left(\mathrm{OR}_{\mathrm{dom}}=1.52, P=0.016\right)$ [69]. These later data also suggested evidence for heterozygote advantage $\left(\mathrm{OR}_{\mathrm{A} / \mathrm{G}}=1.48, P=0.048 \mid \mathrm{OR}_{\mathrm{A} / \mathrm{A}}=1.11, P=0.12\right)$ in the context of a simple genotype model; however adjustments for multiple testing were not included. Lymphocytes from TNF$308 \mathrm{~A}$ individuals had increased TNF secretion in vitro in response to challenge with $\mathrm{Ct}$ elementary bodies. Curiously, the TNF-308A polymorphism has also been identified [70] as a protective factor in trichiasis $\left(\mathrm{OR}_{\mathrm{A} / \mathrm{G}}=0.45[0.25-0.81]\right.$, $\left.P=0.008 \mid \mathrm{OR}_{\mathrm{A} / \mathrm{A}}=0.19[0.04-1.08], P=0.062\right)$ in a study that also identified homozygosity at a lymphotoxin alpha (LTA) polymorphism (LTA252 $\mathrm{OR}_{\mathrm{A} / \mathrm{A}}=0.25$ [0.09-0.63], $P=0.004)$, heterozygosity at an Interleukin 9 polymorphism (IL9-T113M OR $_{\mathrm{C} / \mathrm{T}}=0.25$ [0.1-0.64], $P=0.004$ ), and heterozygosity at the vascular cell adhesion molecule 1 (VCAM1, $\mathrm{OR}=0.47$ [0.25-0.86], $P=0.015)$ as protective factors for trichiasis [70]. The same authors suggested that epistasis between the polymorphisms was potentially key to unraveling the host genetic background of trachoma. TT risk increased substantially ( $\mathrm{OR}=13.5, P=0.001$ ) when the TNFA (-308G), VDR (intron G), IL4R (50 V), and ICAM1 $(56 \mathrm{M})$ polymorphisms were considered as genetic constellations under a "logic regression" model [70], but the number of samples contributing to this analysis was small (controls $n=232$ and $\operatorname{TT} n=135$ ).

A series of studies used SNP genotypes and linkage disequilibrium data to predict haplotypes and then carried out haplotype based association tests in genes including IFN $\gamma$ [71], IL8 [72], IL10 [71, 73], haptoglobin (HP), GM-CSF2 [72], and matrix metalloproteinase 9 (MMP9) [74]. The MMP9 gene is consistently differentially expressed between cases and controls of several stages of trachomatous disease [34, 36]. A study of the IL8/CSF2 loci [72] also noted some evidence for epistatic interactions between polymorphisms in $M M P 9$ and each of the IL 8 and CSF2 genes. Other epistatic interactions were also found in the same dataset, in particular, an MMP9IL10 interaction (Figure 2). In the analysis of a cohort of 651 scarring case-control pairs, main effects for the IL10-1082 allele were null; however interaction between IL10-1082 and MMP9 Q279R contributed to risk. The protective effects of the MMP9 Q279R G allele were transformed to risk in the copresence of a SNP (IL10-1082) tagging the trachoma risk haplotype (IL10-3575A IL10-1082C IL10-592G IL10+5009G). 


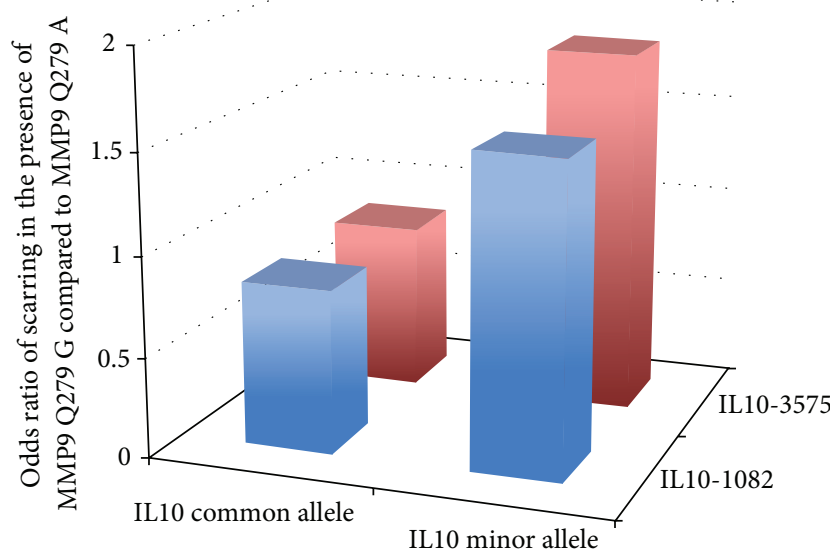

FIGURE 2: Evidence for MMP9-IL10 epistasis in Gambians with trachomatous scarring. The protective effect of $M M P 9$ allele (Q279R) is modulated by host genetic background at the IL10 locus such that protective effects of the $\mathrm{G}$ allele are lost in the presence of either of 2 minor frequency risk alleles (IL10-1082C or IL10-3575A). The interaction between these nonallelic genes (or risk genotypes) has a dominant effect over other combinations. The interaction between risk genotypes was examined by conditional likelihood ratio tests (LRT) (main effects) $\log \mathrm{p} / 1-\mathrm{p}=\mathrm{a}+\mathrm{b}(\mathrm{SNP} 1)+\mathrm{c}(\mathrm{SNP} 2)$. Interaction terms were defined as $\log p / 1-p=a+b(S N P 1)+$ $\mathrm{c}(\mathrm{SNP} 2)+\mathrm{d}(\mathrm{SNP} 1 * \mathrm{SNP} 2)$ and when significant identified statistical epistasis. This approach was applied to $651 \mathrm{Gambian}$ case-control pairs of TS. The MMP9 Q279R and IL10-3575 loci showed strong evidence for statistical interaction affecting risk of TS (LRT $\chi^{2}=$ 7.23, $P=0.007$ ). Carriers of the (protective) $M M P 9$ Q279R G allele who also had the IL10-3575A minor allele were at significantly increased risk of TS $(\mathrm{OR}=1.83(1.06-3.19))$ when compared to subjects with the IL10-3575 $\mathrm{T}$ allele (common allele) $(\mathrm{OR}=0.84$ (0.69-1.02)). The IL10-1082 C minor allele in combination with the MMP9 Q279R G allele had an increased risk of TS (OR $=1.51(1.02-$ 2.24)) relative to IL10-1082 C in the presence of the $M M P 9$ Q279R A allele $(\mathrm{OR}=0.82(0.67-1.01))\left(\mathrm{LRT} \chi^{2}=7.53, P=0.006\right.$ for the interaction between the IL10-1082 and MMP9 risk alleles). Interaction between IL10-1082 and MMP9 Q279R affects risk despite the null single SNP main effect for IL10-1082 [71]. The individually protective MMP9 Q279R G allele was therefore associated with an increased risk of scarring in the presence of IL10 risk alleles (IL10-1082C or IL10-3575A minor alleles) and a decreased risk in the presence of common IL10 (protective) alleles. Similar modelling at other loci previously investigated in this cohort (IFN $\gamma$-1616, +3234; LTA -252, +77; IkBL -63; IL-8 -251; GM-CSF2 27348, 27438) showed significant or marginally significant evidence for two-way interactions, at the genotype or allelic level, with the MMP9 Q279R SNP. Some of these SNPs are in high LD and therefore not all the hypotheses tested are independent. The existence both of LD between loci and of potential biological interdependence between loci raises methodological difficulties in correction for multiple testing. We did not attempt any correction for multiple testing: and therefore a contribution of chance to these results is difficult to exclude as we point out in the main text. Comparing main and additional twoway epistatic effects in the final model suggested that the inclusion of interaction terms improved the fit of the model to the data, so that the final best model included both main and epistatic effects. For TS this model suggested that two-way interactions of MMP9Q279R with IFN $\gamma$-1616, IFN $\gamma+3234, I L 10-1082, I L 8-251, L T A+77$, $L T A-252$, and $I k B L-63$ improved the fit of the model (data courtesy of Natividad, Mabey, Holland, and Bailey).
This allele or haplotype is associated with higher levels of IL10 transcription [73]. This may suggest that premature or excessive downregulation of MMP9 activity by IL-10 ultimately increases risk. Each of these studies suffers from limited sample size and large numbers of parallel statistical tests under several different genetic models, whilst sometimes also considering multiple phenotypes (i.e., scarring and trichiasis). Consequently the results should be interpreted in the context of potential type I and type II errors.

The candidate gene approach has helped reinforce current lines of investigation but has yet to resolve the paradigm of the cellular versus immunological hypotheses or generate new avenues of investigation into the basic biology of chlamydial ocular disease. A genome-wide association scan (GWAS) is an alternative to the candidate gene method and provides an opportunity to generate new hypotheses in an unbiased manner. GWAS requires much larger sample sizes than have been previously described in trachoma and chlamydial urogenital disease and has its own limitations, particularly when applied to samples from African populations [75]. There are also relatively few GWAS in infectious disease [76]. The West African malaria GWAS is perhaps a cautionary example [77]. The study showed that SNP markers in very close proximity to the well-characterized causal SNP (rs334) of the "sicklecell trait" protective effect failed to reach genome-wide significance, even though the study was well powered. This was largely due to the low degree of linkage disequilibrium (LD) between SNPs in African populations. The rs334 SNP, when directly genotyped, was highly significant $\left(P=1.3 \times 10^{-28}\right)$, whilst the best marker in the GWAS SNPs $\left(P=3.9 \times 10^{-7}\right)$ did not reach genome-wide significance. The use of more densely populated GWAS SNP arrays and imputation methods can increase the likelihood of finding significant SNPs [78], but imputation is essentially dependent on LD structures and the imputation of rs334 in the malaria GWAS was far less effective $\left(P=4.5 \times 10^{-14}\right)$ than direct genotyping of the locus [77]. GWAS in African populations are less likely to directly identify SNPs or alleles in association with disease than equivalently sized studies in other populations. Therefore the utility of a trachoma GWAS will most likely be in prioritizing the best candidates and biologically plausible pathways. The small effects of numerous polymorphisms in functionally linked networks potentially have much greater contribution to disease when tested en masse. Several groups are currently pursuing genome-wide approaches to the understanding of the host genetics of chlamydial diseases, either in human clinical populations of pelvic inflammatory disease [79], trachoma [80], and advanced recombinant inbred mouse models [81] or in "cellular GWAS," which uses in vitro infection of extensively genotyped host cell lines $[82,83]$. The potential power of a pathway-focus in genome-wide studies is evident from the preliminary reports in trachoma [80] and a mouse model system [81], both of which emphasize the importance of G-protein coupled receptor signaling pathways in disease processes relating to chlamydial infections.

\section{Chlamydial Genomics and Pathogenesis}

Initial single gene, multilocus sequence typing, and subsequent whole genome sequencing (WGS) of chlamydial species have provided insight into the processes involved in 
chlamydial pathogenesis. The first fully sequenced Chlamydia trachomatis genome was a laboratory reference strain $(\mathrm{D} / \mathrm{UW}-3 / \mathrm{Cx})$ passaged in the laboratory for more than 30 years after its initial isolation from a cervical swab in 1965. The genome was completed by shotgun sequencing using highly purified $\mathrm{C} t$ genomic DNA obtained by bulk culture to produce sufficient genomic DNA to generate the M13 linkeradaptor library. More than 28,000 sequencing reactions using dye-labeled primers and almost 4,700 dye-terminator reactions were required to complete the genome [84]. Ten to twelve years later, the first ocular chlamydial genomes were fully sequenced prior to the wide scale introduction of next generation sequencing (NGS) [85, 86]. Comparative genomic analysis of these and subsequent chlamydial isolates demonstrated overall similarity in gene content and order across biovars and between chlamydial species [87-90]. This high level synteny is correlated with the extent of evolutionary divergence [90]. Application of NGS technologies has rapidly advanced and expanded our understanding of chlamydial comparative and evolutionary dynamics. Recent WGS analysis demonstrated that there is extensive recombination within and between biovars [91] (also noted in other studies [92, 93]) and that there is evidence for genetic exchange and recombination within the cryptic plasmid [91]. This has challenged our knowledge of chlamydial diversity and highlighted the implications of recombination in pathogenesis. Other significant advances including genetic manipulation of Chlamydiae [94, 95], mutagenesis studies [95-98], and axenic culture [99] facilitate the study of chlamydial metabolism and physiology in the context of genetic studies. Novel presequencing enrichment techniques such as immunomagnetic separation and DNA-baiting techniques (SureSelect) have removed technical barriers to obtaining WGS data directly from clinical specimens $[100,101]$. Moreover, the ability to obtain WGS data directly from clinical samples without the need for culture obviates the problem of in vitro propagation and subsequent loss of genomic diversity reflecting differences between in vitro and in vivo evolutionary environments, as has been demonstrated in $C t$ [102-104] and herpesvirus species (Varicella Zoster Virus and Cytomegalovirus) [105, 106]. This allows the study of genetic variants associated with disease, including those under positive selective pressure through interaction with the host. Direct and targeted deep resequencing has also enabled discovery of mixed infections within seed stocks of cultures and from clinical isolates $[104,107]$. Putative virulence factors identified through WGS analysis and in vitro and animal studies include the polymorphic outer membrane protein family (Pmps) [84, 108110], type three secretion system (T3SS) and effectors [111113], genes involved in tryptophan [114-116] and glycogen $[94,117]$ biosynthesis, members of the incA $[118,119]$ and phospholipase-D $[120,121]$ families, genes from the heat shock protein family $[122,123]$, the chlamydial cytotoxin [124], and plasmid-encoded genes implicated in the regulation of chromosomal virulence factors $[97,125,126]$.

Pmps appear to fulfill several biological functions, but the full extent of their role is not entirely clear. These exported bacterial proteins have been shown to function as autotransporters within the chlamydial outer membrane
[127-129]. Several chlamydial Pmps have been detected on the chlamydial elementary body surface [127]. Some are strongly immunogenic and elicit a proinflammatory response [127]. They may play a role in virulence regarding modulation of inflammation and adherence to and invasion of host cells [129].

The chlamydial plasticity zone (PZ) is the site of extensive genomic variation between the chlamydial serovars $[88,90]$. The $\mathrm{PZ}$ contains a toxin whose function is thought to involve GTPase inactivation and guanylate binding protein neutralization resulting in interferon gamma (IFN $\gamma$ ) resistance [124, $130,131]$. IFN $\gamma$ stimulation of cells in vitro and in vivo induces transcription of genes that cooperate to eliminate intracellular bacteria, suggesting that inhibition of this mechanism may contribute to the pathogenesis of chlamydial disease [131]. The genomic organisation of the cytotoxin varies such that oculogenital strains have a single gene with a large deletion and lymphogranuloma venereum (LGV) strains lack the gene entirely, whilst the closely related C. muridarum $(\mathrm{Cm})$ has three intact copies $[132,133]$. This most likely reflects the IFN $\gamma$ evasion mechanism employed by $\mathrm{Cm}$ in the mouse compared with that employed by urogenital strains in humans [133]. Since ocular strains lack a functional trp operon and only have a partial toxin, how they evade IFN $\gamma$ is not fully understood. The membrane attack complex/perforin protein (CT153) and members of the phospholipase-D (PLD) family are also encoded within the PZ [90]. The PZ PLDs are present in $C t$ [120] and other Chlamydiaceae [87, 134, 135]. These proteins are known to modify lipids and membranes and may be secreted and localize to the inclusion membrane [121]. Reactivation of $\mathrm{Ct}$ from an IFN $\gamma$-induced persistent state is blocked by primary alcohols (potent PLD inhibitors), implying a role for PZ PLDs in this process [136].

Genomic analysis has shown that many Inc proteins are produced by each chlamydial species and several are produced early in development. Inc proteins, which are T3SS effector proteins, may be important antigens in cellmediated immune responses following infection. IncA has been defined as an effector protein proposed to mediate inclusion fusion in $C t[118,119]$. IncA proteins exhibit an innate ability to form vesicles and enter the membrane of intracellular compartments [137]. A recent study of the Inchuman "interactome" using affinity-purification mass spectrometry identified that 38/58 Incs interacted with human proteins [138]. Many of the host targets were also targeted by viral proteins implying conserved mechanisms of intracellular pathogenesis. IncE bound to components of the retromer, which restricted chlamydial growth [138].

Work on the chlamydial T3SS [112] in combination with the advent of WGS demonstrated that a family of chlamydial proteins that localize to the inclusion membrane during intracellular growth were a candidate T3SS [111]. This system is important in bacterial pathogenesis and is essential for virulence of a number of bacterial species [139]. In most of these pathogens, the structural and effector genes are located on distinct pathogenicity islands [140]. In Chlamydiae, these genes are scattered across a number of operons and use a sigma factor for constitutive gene expression, suggesting that additional activators or repressors are required if components 
of the T3SS are developmentally regulated [113]. Given the intracellular existence of Chlamydiae, these T3 secreted products are likely to be important in pathogenesis.

The chlamydial plasmid has been shown to function as a virulence factor in animal models [49, 141]. Phenotypic differences vary between plasmid-cured and wild-type strains with respect to infectivity, glycogen accumulation, induction of inflammation, and activation of toll-like receptor pathways $[117,142]$. Plasmid deletion mutagenesis studies showed that deletion of the plasmid-encoded $p g p 4$ gene results in an in vitro phenotype identical to that of a plasmid-free strain [97]. Bacterial transcriptome analysis found a decrease in transcript levels of a subset of chromosomal genes in a naturally occurring plasmid-free strain of $C t$, demonstrating that the plasmid is a transcriptional regulator of virulence-associated genes [125]. Maintenance of the plasmid at the relatively low copy number of 5-6 plasmids per genome [143] carries inherent risk of plasmid-loss during cell partition [144], but naturally occurring plasmid-free strains are rare [145147]. This suggests that 5-6 plasmid copies may maximize infectivity or intracellular survival whilst provoking minimal host immune response. Recent host transcriptome studies suggest that the plasmid may stimulate host cell expression of PD-L1, which induces programmed cell death in immune effector cells $[48,148]$. The plasmid is clearly strongly selected for during successful infection or transmission [142] and recent studies have shown that a plasmid-cured $C t$ strain is less virulent in ocular infection of macaques and can function as a live attenuated vaccine [49].

The ability to obtain WGS data directly from clinical samples enables a genome-wide approach to investigate associations with disease phenotype and chlamydial load in naturally occurring $C t$ infections. Pathogen GWAS studies are a powerful tool to assess the association between a SNP or locus and defined phenotypes. It has also been shown to be a robust approach for discovering novel loci of interest in other bacterial pathogens $[149,150]$. A small number of bacterial GWAS have revealed pathogen genetic associations with host adaptation in Campylobacter jejuni and Escherichia coli [151], drug resistance in Mycobacterium tuberculosis [152], methicillinresistant Staphylococcus aureus (MRSA) [153], and Streptococcus pneumoniae [154] and resulted in the identification of virulence loci in methicillin-resistant Staphylococcus aureus [149]. Rapid advances in WGS techniques will enhance our understanding of chlamydial biology and diseases pathogenesis.

\section{Bacterial Ecology of the Conjunctiva and Trachoma}

Persistent, severe inflammation is associated with conjunctival scarring yet $C$. trachomatis is rarely detected in the eyes of adults with disease signs [7]. This has led to the suggestion that the inflammation seen in trachomatous disease is driven, at least in part, by nonchlamydial pathogens and there is now a growing evidence to support this hypothesis [155].

Studies carried out in The Gambia in the early 2000s found that whilst viable bacteria, including Staphylococcus aureus and Streptococcus species, could be cultured from the eyes of healthy controls, bacterial infection was more frequently identified in the eyes of cases with trachomatous trichiasis [156]; Streptococcus pneumonia was the dominant pathogen isolated. In trachoma endemic communities in Tanzania, individuals with TS have been shown to be more frequently infected with Streptococcus pneumoniae, Haemophilus influenzae, coagulase-negative Staphylococcus, and Corynebacterium species than individuals with normal conjunctivae [155]. Similar findings have been reported in Ethiopians where comparison of the bacterial flora of conjunctivae with trachomatous trichiasis versus trachomatous scarring revealed increased frequency of isolation of Streptococcus pneumoniae, Haemophilus influenzae, coagulase-negative Staphylococcus, Corynebacterium, and viridans streptococci species [157].

More recent studies have examined the presence of viable bacteria in the eyes of children in regions of Tanzania and The Gambia where there is a low prevalence of clinical signs of active trachoma with correspondingly low levels of ocular C. trachomatis infection. In both studies, children with TF were more likely to have nonchlamydial bacteria in their eyes, namely, Streptococcus pneumoniae or Haemophilus influenzae, than children who had no clinical signs of disease $[158,159]$. In the Tanzanian studies, culture of these nonchlamydial bacterial infections was associated with increased host conjunctival expression of IL17A, CXCL5, CCL18, and KLRD1 [37]. Of these, IL17A, CXCL5, and CCL18 were also associated with follicular and papillary inflammation.

The suggestion that nonchlamydial bacterial infection of the eye contributes to the maintenance of an inflammatory state that drives the scarring process is further supported by immunological studies. In Tanzania, a study of individuals with TS in the absence of TT found that nonchlamydial bacterial infection was associated with increased expression of INDO, S100A7, DEFB4A, and MMP12 and decreased expression of MMP10, SPARCL1, and CFH [38]. Clinical inflammation, which is consistently identified as a major risk factor for progressive scarring, was associated with increased INDO, IL1B, DEFB4A, CXCL5, MMP7, MMP9, MMP12, and CD83 and decreased MMP10, SPARCL1, and CFH. Data from longitudinal studies on recurrent trichiasis in The Gambia have indicated that bacterial infection, particularly with Streptococcus pneumonia, and clinical inflammation are associated with recurrence following surgery [160]. Clinical inflammation and nonchlamydial bacteria were also associated with increased expression of IL1B and MMP9 in this cohort [161].

The isolation, often at high loads, of bacteria such as Streptococcus pneumoniae from the eyes of individuals with trachoma may suggest that colonization exacerbates clinical signs of the disease or, alternatively, that those with conjunctival inflammation are more susceptible to colonization and conjunctival scarring. Findings indicating increased numbers of what are largely regarded as commensal bacteria (such as coagulase-negative staphylococci and Corynebacterium species) in trachomatous eyes are also of particular interest, as alterations or dysbiosis of the microbiota could be a contributing factor to disease.

The study of the "normal" or indigenous microbiota that colonizes the human body has seen huge advances in 
the past decade with the application of NGS techniques that enable the identification of viral, fungal, and bacterial species. These methods have been particularly useful in the identification of noncultivable bacteria directly from clinical samples. These techniques have been perhaps best utilized to describe the microbiota of the human gastrointestinal tract and, in particular, changes in the microbiota associated with inflammatory disease including inflammatory bowel syndrome and Crohn's disease. Biopsied intestinal tissue that is inflamed tends to have reduced bacterial species diversity and altered species composition as compared to tissue taken from healthy controls [162-164]. The species composition of the microbiota has also been found to play an important role in the health of the epithelial barrier via induction and maintenance of IL-17, IL-22, and regulatory T cells [165-167].

In the female genital tract, dysbiosis of the microbiota (characterized by decreased numbers of lactobacilli and polymicrobial overgrowth of anaerobic bacteria) is associated with bacterial vaginosis. This and other alterations in the vaginal microbiota are thought to be risk factors for reduced fertility [168]. While the mechanism behind this is not yet clear, bacterial vaginosis has been associated with elevated cervical levels of IL- $1 \beta$ and IL-8, leading to the suggestion that the induction of proinflammatory cytokines by the altered vaginal microbiota is an unrecognized cause of infertility [169].

At present, the metagenome of the ocular surface has not been characterized and, to date, only a handful of studies have applied NGS techniques, namely, deep-sequencing of the 16S rRNA gene, to the characterization of the conjunctival microbiota. A study of four healthy American volunteers described a "core" conjunctival microbiota consisting of Pseudomonas, Propionibacterium, Bradyrhizobium, Corynebacterium, Acinetobacter, Brevundimonas, Staphylococcus, Aquabacterium, Sphingomonas, and Streptococcus species [170]. In contrast, the core members of the conjunctival microbiota of a West African population were identified as Corynebacterium, Streptococcus, Propionibacterium, Bacillus, and Staphylococcus species [171, 172]. Amongst ophthalmologists and microbiologists, these results have been questioned since the traditional view regards the ocular surface as a sterile site of low biomass. This view is not confined to those studying the ocular surface; there are many parallels with those investigating the lung microbiome where there was initial resistance to the concept that the lung was not a "sterile" environment but in fact that healthy lung harbors a complex community of bacteria [173].

Later studies on the conjunctival microbiota in Gambians with trachoma used a case-control study design with and without trachomatous disease (TF, TS, and TT) [172]. In common with other pathologies of the mucosal epithelia, this study found a disequilibrium of the normal flora, as defined by the decreased richness (number of genera) and diversity (number of genera and their abundance within the community) associated with clinical signs of TS and TT when compared with those with healthy eyes [172]. The decrease in bacterial diversity seen in individuals with TS was largely driven by an increase in Corynebacterium species in those with trachomatous disease, which is consistent with earlier studies characterizing the bacterial profile of the eye using culture techniques. The ocular microbiota of children was found to have greater richness and diversity in comparison to that of adults. While few significant differences were found in the microbiota of children with follicles versus normal controls, the microbiota of one child with clinical inflammation was dominated by Haemophilus species again pointing to the potential role of nonchlamydial bacteria in driving inflammation.

One drawback of the 16S rRNA gene sequencing approach, particularly in low biomass samples such as conjunctival swabs, is the potential for contamination from environmental sources and the inability to distinguish between viable and nonviable bacteria. Low biomass samples also currently preclude WGS approaches that would facilitate more a complete characterisation of the bacterial species and the full metagenome (archaea, fungi, and viruses). Using $16 \mathrm{~S}$-amplicon sequencing, it is difficult to distinguish those bacteria that actively colonize the conjunctival surface from those that are transiently introduced into this niche [172]. Primer-bias, which can lead to misrepresentation in the population [174], and bias introduced by sequencing depth, which limits the ability to characterise those bacteria that comprise the minority of the population [175], are also limitations of the $16 \mathrm{~S}$ sequencing approach. As a result, there have been attempts to develop methods that might distinguish viable from nonviable bacteria before entry into the sequencing pipeline, such as the introduction of a DNase I predigestion [176], or the use of community transcriptomics to identify expressed bacterial components.

Culturomics is a relatively new field that couples highthroughput culture with matrix-assisted laser desorption ionization time-of-flight mass spectrometry (MALDI-TOF MS) identification and is a technique that may provide further means of addressing some of these issues. Studies of the gut microbiota have developed culturomics to identify bacterial species never before associated with the human gastrointestinal tract as well as novel species not previously described $[177,178]$. As this technique targets viable cells, it is less prone to artefacts resulting from bacterial DNA contamination. The technique has also been used to establish cell-free Chlamydia trachomatis culture, using radiolabelled amino acids to demonstrate metabolic activity [99]. Culturomics therefore offers the potential to close the gap between 16Samplicon sequencing and traditional microbiological culture $[177,179]$.

New applications of NGS continue to evolve in infectious disease immunology and the study of the role of the microbiota and specific microorganisms. One such technique is IgA-SEQ, a method that utilizes flow cytometry based sorting to separate bacteria coated with IgA from noncoated bacteria in a complex sample. The sorted fractions are then analysed by $16 \mathrm{~S}$-amplicon sequencing to identify the bacteria. In two recent studies, IgA-coated intestinal bacteria identified from human volunteers suffering inflammatory bowel disease and impaired gut-barrier function were cultured. These cultures were then able to induce intestinal inflammation in germ-free mice $[180,181]$. These findings suggested that those bacteria that are able to penetrate the mucin barrier are more likely 
to stimulate an immune inflammatory response. The IgASEQ method thereby provides an elegant means of identifying and isolating those bacteria within the microbiota that drive disease.

The application of sophisticated techniques to the study of the conjunctival microbiota may offer better opportunities to distinguish bacterial colonizers from bystanders as well as identifying those bacteria that stimulate the immune responses that drive inflammation and the scarring process. The analysis of metagenomic data alongside host transcriptome arrays may also aid in this search; unraveling the interactions between the conjunctival microbiota and the gene expression networks and pathways of inflammation that lead to fibrosis is key to further understanding of microbiotahost interactions in scarring disease.

\section{Epigenetics and Chlamydial Infection}

One possible explanation for the chronic inflammation and continued presence of active disease signs in populations once ocular $C t$ infection has been controlled is epigenetic change of the host cell state. "Epigenetics" describes changes in gene expression that are heritable through cell division, without alteration to the DNA sequence itself. These changes can be applied directly to DNA (CpG methylation), to the proteins DNA is packaged around (chromatin modifications such as histone methylation or acetylation), and to the transcribed message (microRNA mediated silencing).

Bacteria and infection-induced inflammation are both known to induce epigenetic changes in host cells, particularly to genes in the MAPK, NFkB, and IFN $\gamma$ signaling pathways, all of which are integral to the immune response (reviewed in [182]). Helicobacter pylori induces genome-wide aberrant hypermethylation of DNA in the gastric mucosa of pediatric and adult samples [183]. In particular, methylation of Ecadherin (and its downregulation, which is a characteristic of epithelial-mesenchymal transition (EMT), discussed further below) is induced by $H$. pylori infection via IL- $1 \beta$ stimulation of $\mathrm{NFkB}$, resulting in nitric oxide production and activation of DNA methyltransferases [184]. In a similar manner, the Bacille Calmette-Guerin (BCG) vaccine induces longlasting and nonspecific increases in cytokine expression in human monocytes via NOD2-dependent histone methylation of H2K4me3 [185]. Chlamydia encode SET (suppressor of variegation-enhancer of zeste-trithorax) domain proteins, which function as methyltransferases [186]. Ct encodes nuclear effector (NUE), a SET domain histone methyltransferase which is secreted through the T3SS and shows activity toward histones $\mathrm{H} 2 \mathrm{~B}, \mathrm{H} 3$, and $\mathrm{H} 4$ in the host cell nucleus [187]. As of yet, the targets and function of NUE in the host remain to be identified. Humphrys and colleagues found that a number of host genes encoding histones were differentially expressed at 1 hour after infection, perhaps reflecting an early modulatory effect of $C t$ infection on the host epigenetic profile [188]. It is tempting to speculate that $C t$ stimulation of pathogen recognition receptors may induce $\mathrm{CpG}$ or histone methylation changes, or in fact that $C t$ may directly induce host histone changes via NUE, causing an abnormal state of chronic inflammation in the conjunctival epithelium.

\section{The Role of Small RNAs in Chlamydial Disease}

Only $20 \%$ of transcription across the human genome is associated with protein-coding genes [189] and it has become clear that many of the non-protein-coding RNA species that are transcribed have important regulatory roles. These noncoding RNA species include microRNA (miRNA), short interfering RNA (siRNA), piwi-interacting RNA (piRNA), small nucleolar RNAs (snoRNA), other small RNAs, and long noncoding RNA (lncRNA (>200 nucleotides)).

miRNA encoding sequences make up only around $2 \%$ of the human genome but are estimated to regulate $>60 \%$ of protein-coding genes [190]. miRNA (miR) are short (18-22 nucleotides) single stranded sequences of RNA. miR regulate gene expression through binding to complementary messenger RNA (mRNA) sequences in the cytosol in association with Argonaute proteins, forming a RNA-induced silencing complex (RISC), leading to inhibition or degradation of the target mRNA [191]. The "seed sequence" of the miR, nucleotides 2-7 from the five prime ends, guides target selection [192]. Half of known miR are found in polycistronic units and are expressed in parallel, often sharing structure and function $[193,194]$. Due to flexibility in binding complementarity, an individual miR can target hundreds of different genes and a gene might be targeted by many different miR [194], forming a complex network of regulation. Abnormal expression of miR may occur by the same factors regulating expression of any gene, including epigenetic control of premiR transcription or SNPs in the miR coding sequence. miR expression can also be regulated at the posttranscriptional level (as pre-miR or mature miR), by RNA-binding proteins or by circular RNAs that can act as "sponges" [195-198]. Due to the far-reaching and complex roles of miR, a small change in expression can have a profound effect on tissue homeostasis.

miR are an important part of the host response to bacteria, both pathogenic and commensal. Inflammation must be tightly regulated; excess can lead to organ damage whereas insufficient inflammation may facilitate the dissemination of infection. Several miR are well characterized as having important roles in the immune response against bacteria (reviewed in [199-201]). miR-146 and miR-155 are upregulated in immune cells following infection with a range of bacteria, including Helicobacter pylori, Salmonella enterica, Listeria monocytogenes, Francisella tularensis, and Mycobacterium species. Both miR-155 and miR-146 function in negative feedback loops to prevent excessive inflammation by silencing targets in the TLR4 signalling pathway. miR155 also maintains TNF expression and is essential for an appropriate adaptive immune response. Distinct patterns of $\mathrm{miR}$ expression are elicited by two strains of $\mathrm{Cm}$ that vary in virulence in the murine genital tract [202]. miR-223-3p and miR-18a-5p were induced in mice by both strains at 24 hours after infection. Interestingly, miR-155 expression was increased in response to avirulent $\mathrm{Cm}$ but not in response to the virulent strain of $\mathrm{Cm}$. The failure to upregulate miR155 in the virulent infection could indicate an absence of the negative feedback loop that is required to prevent excessive 
inflammation, leading to the increased pathology that was observed. Gupta and colleagues investigated miR expression following $\mathrm{Cm}$ infection in the murine genital model at a later time point. At 6 days after bacterial challenge, miR125b-5p, miR-135a, miR-16, miR-214, miR-30c, miR-30e, miR182 , miR-183, and miR-23b were downregulated in the lower genital tract and miR-146 and miR-451 were upregulated [203]. These changes were not maintained at 12 days after infection. Knockdown of miR-125b-5p, miR-30c, and miR182 led to a failure to control $\mathrm{Cm}$ infection and, in $\mathrm{CD} 4^{-/-}$ mice, levels of miR-125b-5p, miR-182, miR-183, and miR-135 were upregulated relative to wild-type infected mice. miR$125 \mathrm{~b}$ maintains the naivety of $\mathrm{T}$ cells and is downregulated upon their differentiation and maturation [204]. miR-125b also targets TNF and is thought to maintain the inactivity of macrophages in the absence of bacterial TLR stimulation [199]. miR-125b downregulation may therefore be required for an appropriate immune response. Igietseme and colleagues have shown that, upon urogenital infection of mice with a virulent LGV $C t$ strain (L2), murine miR-21, miR103, miR-107, let-7i, and miR-92b were downregulated in the oviducts, though the time point at which these changes in expression are observed is unclear [205].

Overexpression of miR-146a in psoriatic skin lesions has been linked to a SNP in the miR-146 gene in a large cohort of Chinese patients [206]. Wang and colleagues looked at the association of polymorphisms in miR-146a and the NRLP3 inflammasome in association with susceptibility and severity of urogenital $C t$ infection in two cohorts of Dutch and Finnish women [207]. A SNP in NLRP3 was found to associate with lower abdominal pain in $\mathrm{Ct}$ positive women; however, no link with miR-146a was found. Our previous work has identified that miR-147b is upregulated in scarring and inflammatory trachoma and miR-1285 is upregulated in scarring and inflammation when compared to scarring alone [208]. miR-147b acts in a similar manner to miR146a; it is induced by TLR signaling and prevents excessive inflammation in murine macrophages [209] and is thought to have a homologous role in humans [210]. The upregulation of miR-147b in diseased individuals could represent repeated TLR stimulation, perhaps by an abnormal microbiome. miR1285 has conflicting roles in regulation of the cell cycle [211, 212]. Abnormal regulation of inflammation and cell cycle could drive the chronic inflammation and fibrotic proliferation associated with trachomatous pathology.

Transcriptome arrays comparing gene expression at various stages of trachomatous disease have found that many thousands of genes are differentially regulated $[34,36]$. In an attempt to reduce this complexity, we used a data mining approach (MSigDB) and found miR that were enriched for targets within lists of differentially regulated genes of four trachoma transcriptomes (Table 1). Of interest are the miR with known roles in the regulation of EMT, which we discuss further below. A number of miR that have been identified as differentially expressed in $\mathrm{Ct}$ and $\mathrm{Cm}$ infection are enriched for targets in these datasets, particularly in the comparison of active disease with $C t$ infection against controls, which is closest biologically to these murine models. Many of the miR were predicted to have roles regulating cell proliferation and apoptosis. This could be reflective of $C t$ preventing host cell apoptosis to maintain the intracellular niche or $\mathrm{T}$ cell and fibroblast proliferation contributing to inflammation and fibrosis; however, a drawback of using data mining techniques is the relative abundance of cancer-related miR associations and pathways that dominate the literature. Pathogens and commensals express their own regulatory RNAs and it is emerging that these can be translocated into host cells to subvert or manipulate the response. Several DNA viruses express $\mathrm{miR}$ that target viral and host mRNAs to enhance their own success and some express virulence factors that manipulate host miR levels (reviewed in [213, 214]). Mycobacterium tuberculosis secreted effector ESAT-6 downregulates let-7f in macrophages, releasing expression of A20, which is a negative feedback regulator of the NFkB pathway [215]. This results in a reduction of inflammatory cytokine production and increased $M$. tuberculosis survival. miR from the parasitic nematodes Heligmosomoides polygyrus and Litomosoides sigmodontis have recently been found in the serum of mice and in discrete parasite-secreted exosomes, resulting in systemic immune regulation and suppression following uptake by host cells [216]. Little is known about bacterial miR and their ability to modulate host responses. Mycobacterium marinum expresses a candidate miR ( $23 \mathrm{nt}$ long) that can be bound by host RISC and silence an mRNA target, though a functional role has not yet been identified [217]. Ct does not appear to express any authentic miR species in human cells, as defined by association with RISC proteins and a length of $22 \pm 2 \mathrm{nt}$ [217]. Ct does, however, encode a number of noncoding RNAs with distinct expression patterns throughout the developmental cycle, one of which regulates the transcription of a $C t$ gene $[218,219]$. Some lncRNA encoding sequences are located on the $C t$ plasmid, a known virulence factor [220]. No effect on chlamydial gene transcription was identified by "knockout" of one of these plasmid-encoded miR, but an effect on host transcription was not examined [97].

\section{Epithelial-Mesenchymal Transition and Chlamydial Disease}

EMT is a reversible process by which epithelial cells differentiate into mesenchymal cells. Currently 3 types of EMT are recognised. In type-I EMT, epithelial cells differentiate into mesenchymal cells to migrate around the growing embryo during fetal development. These mesenchymal cells can then transform back into epithelia through the reverse process of mesenchymal-epithelial transition (MET) to establish new distant sites of epithelial tissue. Type-II EMT is associated with inflammation-induced tissue fibrosis and type-III EMT occurs in cancer when epithelial tumors metastasize. It is thought that the 3 types of EMT have similar stimuli, signaling cascades, and regulation $[221,222]$. Endothelial cells also differentiate into mesenchymal cells when subjected to the same stimuli (EndMT) and can contribute to cardiac fibrosis [223].

Type-II EMT (EMT-2) occurs in response to inflammation and can lead to loss of organ function through pathological fibrosis. Inflammatory cytokines, growth factors, and MMPs activate a chain of transcription factors that 
TABLE 1: miR predicted to regulate differentially expressed transcripts from four array datasets.

MsigDb predicted miR based on differentially regulated mRNA transcripts

(FC $>1.5$ Adj. $P<0.01)$ from 4 trachoma transcriptomes

miR functional categories

\begin{tabular}{|c|c|c|c|c|}
\hline & $\begin{array}{l}\text { Active disease with Ct } \\
\text { infection } \\
\text { (GSE20436) }\end{array}$ & $\begin{array}{l}\text { Active disease } \\
\text { (GSE20430) }\end{array}$ & $\begin{array}{l}\text { disease with } \\
\text { inflammation } \\
\text { (GSE24383) }\end{array}$ & $\begin{array}{l}\text { Trachomatous trichiasi } \\
\text { with inflammation } \\
\text { (GSE23705) }\end{array}$ \\
\hline \multirow{4}{*}{ Inflammation/infection } & let-7 family [205] & & miR-511 & let-7 family [205] \\
\hline & $\mathbf{m i R}-125 a / b[203]$ & & & $\mathrm{miR}-19 \mathrm{a} / \mathrm{b}$ \\
\hline & $\operatorname{miR}-19 \mathrm{a} / \mathrm{b}$ & & & $\operatorname{miR}-224$ \\
\hline & & & & $\mathrm{miR}-29 \mathrm{a} / \mathrm{b} / \mathrm{c}$ \\
\hline \multirow{4}{*}{ EMT/fibrosis } & $\mathrm{miR}-200 \mathrm{~b} / \mathrm{c}, \mathrm{miR}-429$ & & & $\mathrm{miR}-200 \mathrm{~b} / \mathrm{c}, \mathrm{miR}-429$ \\
\hline & miR-506 & & & $\mathrm{miR}-29 \mathrm{a} / \mathrm{b} / \mathrm{c}$ \\
\hline & & & & miR-506 \\
\hline & & & & miR-520d \\
\hline \multirow{12}{*}{ Cell cycle/cancer } & let-7 family [205] & miR-518a-2 & $\mathrm{miR}-128 \mathrm{a} / \mathrm{b}$ & let-7 family[205] \\
\hline & miR-124a & miR-186 & $\operatorname{miR}-21[202,205]$ & $\mathrm{miR}-19 \mathrm{a} / \mathrm{b}$ \\
\hline & miR-125a/b [203] & miR-130a/b, miR-301 & $\mathrm{miR}-26 \mathrm{a} / \mathrm{b}$ & miR-22 \\
\hline & miR-15 family & & $\mathrm{miR}-519 \mathrm{a} / \mathrm{b} / \mathrm{c}$ & miR-224 \\
\hline & $\begin{array}{l}\text { miR-17-5p, miR-20a/b, } \\
\text { miR-106a/b, and miR-519d }\end{array}$ & & & $\begin{array}{l}\text { miR-25, miR-32, } \\
\text { miR-92, miR-363, and } \\
\text { miR-367 [205] }\end{array}$ \\
\hline & $\mathrm{miR}-19 \mathrm{a} / \mathrm{b}$ & & & miR-516-3p \\
\hline & miR-218 & & & $\mathrm{miR}-519 \mathrm{a} / \mathrm{b} / \mathrm{c}$ \\
\hline & $\mathbf{m i R - 2 3 a / b ~ [ 2 0 3 ] ~}$ & & & miR-520d \\
\hline & $\mathbf{m i R - 3 0 a / b / c / d / e - 5 p ~ [ 2 0 3 ] ~}$ & & & \\
\hline & $\mathrm{miR}-519 \mathrm{a} / \mathrm{b} / \mathrm{c}$ & & & \\
\hline & miR-524 & & & \\
\hline & miR-9 & & & \\
\hline \multirow{2}{*}{ Other } & miR-130a/b, miR-301 & & miR-153 & $\mathrm{miR}-27 \mathrm{a} / \mathrm{b}$ \\
\hline & & & & miR-516-5p \\
\hline
\end{tabular}

Phenotype comparisons are as follows: normal healthy (N) children aged 1-9 versus those with active trachoma (TF) and Ct infection (GSE20436); children aged 1-9 with TF (with or without $C t$ infection) versus N (GSE20430); N adults versus adults with trachomatous scarring and clinical inflammation (TSI) (GSE24383); and N adults versus adults with trichiasis and clinical inflammation (TTI) (GSE23705). Enriched miR are grouped into functional categories based on well-characterized roles in the literature. References show published studies that identify miR in bold as differentially expressed in chlamydial infection. cause downregulation of epithelial characteristics in cells and gain of mesenchymal properties. The basement membrane is degraded by MMPs, allowing differentiating cells to migrate into the interstitial tissue [224]. New mesenchymal cells can then acquire a myofibroblast phenotype [225], secreting collagen 1 and expressing $\alpha$-smooth muscle actin and therefore contributing to extracellular matrix deposition and "wound" contraction. EMT-2 is known to contribute to the pathology of many fibrotic diseases, including kidney fibrosis [225], idiopathic pulmonary fibrosis [226], and cardiac and liver fibrosis [223, 227]. In a murine model of liver fibrosis, up to $45 \%$ of fibroblasts were found to have originated from hepatocytes [227]. Evidence of EMT has been shown both in acute wound healing and in chronic fibrotic (hypertrophic) scars where there is also evidence of unresolved inflammation [228]. EMT-2 ceases when inflammatory stimuli stop; therefore it appears that EMT-2 only become pathological in an environment of chronic inflammation. Having said that, EMT cells can be resistant to apoptosis (reviewed in [229]), possibly arising from the need for resilient cells to seed new sites of epithelial tissue in embryonic development. In addition to resisting apoptosis, EMT cells can acquire stem-cell-like properties allowing self-renewal [230-232], a property which is known to play a role in various cancers and which could contribute to the chronic fibrosis that is observed in trachoma. EMT-activating transcription factor ZEB1 represses expression of the stemness-inhibiting miR200 family, therefore releasing expression of stem-cell factors and leading to EMT and self-renewal. From the evidence of our in silico analysis (Table 1), we suggest that the miR-200 family may be associated with trachoma.

Epigenetic changes can fix the expression of genes that induce EMT, contributing to chronic fibrosis and cancer. TGF $\beta$-induced EMT is associated with global loss of 
heterochromatin mark $\mathrm{H} 3 \mathrm{~K} 9 \mathrm{Me} 2$ and gain of euchromatin marks H3K4Me3 and H3K36Me3 [233]. In cancer-related EMT, hypermethylation of E-cadherin is found [234, 235]. SNAIL, a transcription factor associated with EMT, is thought to contribute to this effect by recruiting DNA methyltransferase-1 to the E-cadherin promoter [236] and has been shown to modify the chromatin structure at the site through recruitment of the $\operatorname{Sin} 3 \mathrm{~A} /$ histone deacetylase 1 (HDAC1)/HDAC2 complex [237].

Primary hepatocytes infected with hepatitis $\mathrm{C}$ virus in vitro have been shown to upregulate biomarkers of EMT [238]. LPS-treated intrahepatic biliary epithelial cells upregulate TGF $\beta 1$ in vitro and stimulate EMT through the TGF $\beta 1 /$ SMAD2/3 pathway [239]. EMT-2 has also been observed during herpes virus infection in vitro and in vivo and following E. coli infection in vitro [240, 241]. Helicobacter pylori virulence factors VacA and CagA disrupt epithelial cell tight junctions and polarity [242-244] and upregulation of EMT transcription factors and biomarkers in gastric cell lines requires both the cag pathogenicity island and $\mathrm{NFkB}$ activation $[245,246]$. EMT can thus be stimulated indirectly through inflammatory signals or directly by pathogens. $C t$ infected epithelial cells in ex vivo fallopian tube tissue show phenotypic changes characteristic of EMT, such as decreased polarity and cell adhesion [247]. The WNT pathway was upregulated and $\beta$-catenin was recruited to the chlamydial inclusion. Loss of epithelial cell-cell adhesion, $N$-cadherin $/ \beta$ catenin complex formation, and recruitment of $\beta$-catenin to the chlamydial inclusion have also been observed in vitro [248]. Nectin-1, an integral molecule of epithelial cell tight junctions and adherens junctions, was downregulated at the posttranscriptional level by $85 \%$ in Ct infected HeLa cells, which was dependent on live infection [249]. Disruptions to key components of the WNT and Notch signaling pathways, intercellular junctions and adhesion, and cytoskeletal remodeling have been identified by RNA-sequencing as early as one hour after infection of HeLa cells with serovar E [188]. Transcriptomic profiling of TT and subsequent gene-set enrichment analysis has also shown significant enrichment in members of the WNT pathway $[36,250]$. These data therefore support a role for WNT signaling in both active infection and later stages of chlamydial disease. Given that WNT signaling stimulates EMT in vitro [251] and the Akt/ $\beta$ catenin pathway mediates EMT activation following $\mathrm{HCV}$ and $H$. pylori infection $[238,244]$, it is therefore tempting to speculate that $C t$ induces EMT-2 in the conjunctival epithelium, either directly or via $\mathrm{Ct}$-induced inflammation.

\section{Conclusions}

The development of scarring trachoma represents a complex multigenic system where each host factor contributes a small protective or deleterious risk. Interaction of each of these factors adds a further layer of complexity to understanding of the disease process. Outside of host genetic factors, balance or dysbiosis of the ocular surface microbiome coupled to $C t$ genetic variation and environmental risk factors each contributes to a multilayered disease network that determines protection or pathology. Excessive or uncontrolled prolonged inflammation is the main risk factor for pathology. Genes and pathways that are dysregulated in inflammation, infection, and scarring have been identified, but clear causative links between inflammation and scarring remain elusive. To address this, we need in vitro studies and longitudinal clinical studies of infection, inflammation, and progressive scarring in childhood when scarring evolves. Unlike human sexually transmitted chlamydial infections, studies such as these are still possible in trachoma endemic populations. The current trend [252, 253] and emerging toolkit [254263] for using a systems-wide or systems biology analysis of data promise to look beyond single markers towards entire molecular and cellular pathways across multiple layers of disease. The ultimate goal of the systems approaches should be to define a model that integrates data from these multiple layers including the host genetic background, composition of the microbiome, host response (transcriptome, proteome, and epigenome), and pathogen variation $[188,264]$ in order to explain the route to scarring or protection.

\section{Conflict of Interests}

The authors declare that there is no conflict of interests regarding the publication of this paper.

\section{References}

[1] Sightsavers, "Sightsavers Annual Review: 24," MISC12, 2012.

[2] WHO Alliance, "Weekly epidemiologicalrecord," Relevé épidémiologique Hebdomadaire, vol. 96, pp. 421-428, 2014.

[3] J. D. Keenan, B. Ayele, T. Gebre et al., "Childhood mortality in a cohort treated with mass azithromycin for trachoma," Clinical Infectious Diseases, vol. 52, no. 7, pp. 883-888, 2011.

[4] E. J. Giamarellos-Bourboulis, "Macrolides beyond the conventional antimicrobials: a class of potent immunomodulators," International Journal of Antimicrobial Agents, vol. 31, no. 1, pp. 12-20, 2008.

[5] V. Jimenez, H. C. Gelderblom, R. Mann Flueckiger, P. M. Emerson, D. Haddad, and T. M. Lietman, "Mass drug administration for trachoma: how long is not long enough?” PLoS Neglected Tropical Diseases, vol. 9, no. 3, Article ID e0003610, 2015.

[6] C. L. Coles, K. Mabula, J. C. Seidman et al., "Mass distribution of azithromycin for trachoma control is associated with increased risk of azithromycin-resistant Streptococcus pneumoniae carriage in young children 6 months after treatment," Clinical Infectious Diseases, vol. 56, no. 11, pp. 1519-1526, 2013.

[7] M. J. Burton, S. N. Rajak, V. H. Hu et al., "Pathogenesis of progressive scarring trachoma in Ethiopia and Tanzania and its implications for disease control: two cohort studies," PLoS Neglected Tropical Diseases, vol. 9, no. 5, Article ID e0003763, 2015.

[8] R. G. Rank and L. Yeruva, "Hidden in plain sight: chlamydial gastrointestinal infection and its relevance to persistence in human genital infection," Infection and Immunity, vol. 82, no. 4, pp. 1362-1371, 2014.

[9] A. P. Craig, F. Y. S. Kong, L. Yeruva et al., "Is it time to switch to doxycycline from azithromycin for treating genital chlamydial infections in women? Modelling the impact of autoinoculation from the gastrointestinal tract to the genital tract," $B M C$ Infectious Diseases, vol. 15, article 200, 2015. 
[10] A. R. Last, S. E. Burr, H. A. Weiss et al., "Risk factors for active trachoma and ocular Chlamydia trachomatis infection in treatment-naïve trachoma-hyperendemic communities of the Bijagós Archipelago, Guinea Bissau," PLoS Neglected Tropical Diseases, vol. 8, no. 6, Article ID e2900, 2014.

[11] V. H. Hu, P. Massae, H. A. Weiss et al., "In vivo confocal microscopy of trachoma in relation to normal tarsal conjunctiva," Ophthalmology, vol. 118, no. 4, pp. 747-754, 2011.

[12] V. H. Hu, M. J. Holland, I. A. Cree et al., "In vivo confocal microscopy and histopathology of the conjunctiva in trachomatous scarring and normal tissue: a systematic comparison," British Journal of Ophthalmology, vol. 97, no. 10, pp. 1333-1337, 2013.

[13] D. C. W. Mabey, V. Hu, R. L. Bailey, M. J. Burton, and M. J. Holland, "Towards a safe and effective chlamydial vaccine: lessons from the eye," Vaccine, vol. 32, no. 14, pp. 1572-1578, 2014.

[14] S. Sowa, J. Sowa, L. H. Collier, and W. A. Blyth, "Trachoma vaccine field trials in The Gambia," Journal of Hygiene, vol. 67, no. 4, pp. 699-717, 1969.

[15] R. L. Bailey, M. J. Burton, and D. C. W. Mabey, "Trachoma vaccine trials in the Gambia," in Chlamydial Infections. Proceedings of the Thirteenth International Symposium on Human Chlamydial Infections, J. Schachter, G. Byrne, and M. A. Chernesky, Eds., pp. 485-488, Asilomar Conference Grounds, Pacific Grove, Calif, USA, 2014.

[16] D. C. W. Mabey, V. H. Hu, R. L. Bailey et al., "Towards a safe and effective chlamydial vaccine: lessons from the eye," in Proceedings of the 13th International Symposium on Human Chlamydial Infections, J. Schachter, G. Byrne, M. A. Chernesky, and etal, Eds., pp. 489-492, Asilomar Conference Grounds, Pacific Grove, Calif, USA, June 2014.

[17] V. H. Hu, M. J. Holland, and M. J. Burton, “Trachoma: protective and pathogenic ocular immune responses to Chlamydia trachomatis," PLoS Neglected Tropical Diseases, vol. 7, no. 2, Article ID e2020, 2013.

[18] R. G. Rank, C. Dascher, A. K. Bowlin, and P. M. Bavoil, "Systemic immunization with Hsp60 alters the development of chlamydial ocular disease," Investigative Ophthalmology and Visual Science, vol. 36, no. 7, pp. 1344-1351, 1995.

[19] E. A. Wagar, J. Schachter, P. Bavoil, and R. S. Stephens, "Differential human serologic response to two 60,000 molecular weight Chlamydia trachomatis antigens," Journal of Infectious Diseases, vol. 162, no. 4, pp. 922-927, 1990.

[20] T. Skwor, R. P. Kandel, S. Basravi, A. Khan, B. Sharma, and D. Dean, "Characterization of humoral immune responses to chlamydial HSP60, CPAF, and CT795 in inflammatory and severe trachoma," Investigative Ophthalmology \& Visual Science, vol. 51, no. 10, pp. 5128-5136, 2010.

[21] N. M. Budrys, S. Gong, A. K. Rodgers et al., "Chlamydia trachomatis antigens recognized in women with tubal factor infertility, normal fertility, and acute infection," Obstetrics and Gynecology, vol. 119, no. 5, pp. 1009-1016, 2012.

[22] C. Lu, M. J. Holland, S. Gong et al., "Genome-wide identification of Chlamydia trachomatis antigens associated with trachomatous trichiasis," Investigative Ophthalmology \& Visual Science, vol. 53, no. 6, pp. 2551-2559, 2012.

[23] M. J. Holland, R. L. Bailey, L. J. Hayes, H. C. Whittle, and D. C. W. Mabey, "Conjunctival scarring in trachoma is associated with depressed cell-mediated immune responses to chlamydial antigens," Journal of Infectious Diseases, vol. 168, no. 6, pp. 15281531, 1993.
[24] M. J. Holland, R. L. Bailey, D. J. Conway et al., “T helper type1 (Th1)/Th2 profiles of peripheral blood mononuclear cells (PBMC); responses to antigens of Chlamydia trachomatis in subjects with severe trachomatous scarring," Clinical \& Experimental Immunology, vol. 105, pp. 429-435, 1996.

[25] A. M. Abu El-Asrar, K. Geboes, K. F. Tabbara, S. A. Al-Kharashi, L. Missotten, and V. Desmet, "Immunopathogenesis of conjunctival scarring in trachoma," Eye, vol. 12, no. 3, pp. 453460, 1998.

[26] A. Gall, A. Horowitz, H. Joof et al., "Systemic effector and regulatory immune responses to chlamydial antigens in trachomatous trichiasis," Frontiers in Microbiology, vol. 2, article 10, 2011.

[27] R. C. Brunham and J. Rey-Ladino, "Immunology of Chlamydia infection: implications for a Chlamydia trachomatis vaccine," Nature Reviews Immunology, vol. 5, no. 2, pp. 149-161, 2005.

[28] N. Olivares-Zavaleta, W. M. Whitmire, L. Kari, G. L. Sturdevant, and H. D. Caldwell, "CD8 ${ }^{+} \mathrm{T}$ cells define an unexpected role in live-attenuated vaccine protective immunity against Chlamydia trachomatis infection in macaques," The Journal of Immunology, vol. 192, no. 10, pp. 4648-4654, 2014.

[29] R. S. Stephens, "The cellular paradigm of chlamydial pathogenesis," Trends in Microbiology, vol. 11, no. 1, pp. 44-51, 2003.

[30] S. J. Rasmussen, L. Eckmann, A. J. Quayle et al., "Secretion of proinflammatory cytokines by epithelial cells in response to Chlamydia infection suggests a central role for epithelial cells in chlamydial pathogenesis," The Journal of Clinical Investigation, vol. 99, no. 1, pp. 77-87, 1997.

[31] S. Dessus-Babus, T. L. Darville, F. P. Cuozzo, K. Ferguson, and P. B. Wyrick, "Differences in innate immune responses (in vitro) to HeLa cells infected with nondisseminating serovar E and disseminating serovar L2 of Chlamydia trachomatis," Infection and Immunity, vol. 70, no. 6, pp. 3234-3248, 2002.

[32] Z. Zhu, C. G. Lee, T. Zheng et al., "Airway inflammation and remodeling in asthma. Lessons from interleukin 11 and interleukin 13 transgenic mice," American Journal of Respiratory and Critical Care Medicine, vol. 164, no. 10, pp. S67-S70, 2001.

[33] L. R. Buckner, M. E. Lewis, S. J. Greene, T. P. Foster, and A. J. Quayle, "Chlamydia trachomatis infection results in a modest pro-inflammatory cytokine response and a decrease in $\mathrm{T}$ cell chemokine secretion in human polarized endocervical epithelial cells," Cytokine, vol. 63, no. 2, pp. 151-165, 2013.

[34] A. Natividad, T. C. Freeman, D. Jeffries et al., "Human conjunctival transcriptome analysis reveals the prominence of innate defense in Chlamydia trachomatis infection," Infection and Immunity, vol. 78, no. 11, pp. 4895-4911, 2010.

[35] A. L. Barron, Microbiology of Chlamydia, edited by: A. L. Barron, CRC Press, 1988.

[36] M. J. Burton, S. N. Rajak, J. Bauer et al., "Conjunctival transcriptome in scarring trachoma," Infection and Immunity, vol. 79, no. 1, pp. 499-511, 2011.

[37] M. J. Burton, A. Ramadhani, H. A. Weiss et al., "Active trachoma is associated with increased conjunctival expression of IL17A and profibrotic cytokines," Infection and Immunity, vol. 79, no. 12, pp. 4977-4983, 2011.

[38] V. H. Hu, H. A. Weiss, A. M. Ramadhani et al., "Innate immune responses and modified extracellular matrix regulation characterize bacterial infection and cellular/connective tissue changes in scarring trachoma," Infection and Immunity, vol. 80, no. 1, pp. 121-130, 2012. 
[39] D. J. Conway, M. J. Holland, A. E. Campbell et al., "HLA class I and II polymorphisms and trachomatous scarring in a Chlamydia trachomatis-endemic population," The Journal of Infectious Diseases, vol. 174, no. 3, pp. 643-646, 1996.

[40] R. W. Peeling, R. L. Bailey, D. J. Comvay et al., "Antibody response to the $60-\mathrm{kDa}$ chlamydial heat-shock protein is associated with scarring trachoma," The Journal of Infectious Diseases, vol. 177, no. 1, pp. 256-259, 1998.

[41] L. K. Gaur, R. W. Peeling, M. Cheang et al., "Association of Chlamydia trachomatis heat-shock protein 60 antibody and HLA class II DQ alleles," Journal of Infectious Diseases, vol. 180, no. 1, pp. 234-237, 1999.

[42] C. R. Cohen, S. S. Sinei, E. A. Bukusi, J. J. Bwayo, K. K. Holmes, and R. C. Brunham, "Human leukocyte antigen class II DQ alleles associated with Chlamydia trachomatis tubal infertility," Obstetrics and Gynecology, vol. 95, no. 1, pp. 72-77, 2000.

[43] M. J. Holland, D. J. Conway, T. J. Blanchard et al., "Synthetic peptides based on Chlamydia trachomatis antigens identify cytotoxic T lymphocyte responses in subjects from a trachomaendemic population," Clinical \& Experimental Immunology, vol. 107, no. 1, pp. 44-49, 1997.

[44] O. S. M. Mahdi, H. C. Whittle, H. Joof, D. C. W. Mabey, and R. L. Bailey, "Failure to detect HLA-A*6802-restricted CD8 ${ }^{+}$T cells specific for Chlamydia trachomatis antigens in subjects from trachoma-endemic communities," Clinical and Experimental Immunology, vol. 123, no. 1, pp. 68-72, 2001.

[45] M. J. Holland, N. Faal, I. Sarr et al., "The frequency of Chlamydia trachomatis major outer membrane protein-specific $\mathrm{CD}^{+} \mathrm{T}$ lymphocytes in active trachoma is associated with current ocular infection," Infection and Immunity, vol. 74, no. 3, pp. 1565-1572, 2006.

[46] M. N. Starnbach, M. J. Bevan, and M. F. Lampe, "Protective cytotoxic T lymphocytes are induced during murine infection with Chlamydia trachomatis," The Journal of Immunology, vol. 153, no. 11, pp. 5183-5189, 1994.

[47] S.-K. Kim, L. Devine, M. Angevine, R. DeMars, and P. B. Kavathas, "Direct detection and magnetic isolation of Chlamydia trachomatis major outer membrane protein-specific $\mathrm{CD} 8^{+}$ CTLs with HLA class I tetramers," Journal of Immunology, vol. 165, no. 12, pp. 7285-7292, 2000.

[48] S. C. Fankhauser and M. N. Starnbach, "PD-L1 limits the mucosal CD8 ${ }^{+} \mathrm{T}$ cell response to Chlamydia trachomatis," The Journal of Immunology, vol. 192, no. 3, pp. 1079-1090, 2014.

[49] L. Kari, W. M. Whitmire, N. Olivares-Zavaleta et al., "A liveattenuated chlamydial vaccine protects against trachoma in nonhuman primates," The Journal of Experimental Medicine, vol. 208, no. 11, pp. 2217-2223, 2011.

[50] K. P. Karunakaran, H. Yu, X. Jiang et al., "Outer membrane proteins preferentially load MHC class II peptides: implications for a Chlamydia trachomatis T cell vaccine," Vaccine, vol. 33, no. 18, pp. 2159-2166, 2015.

[51] A. G. White, J. Bogh, W. Leheny et al., "HLA antigens in Omanis with blinding trachoma: markers for disease susceptibility and resistance," British Journal of Ophthalmology, vol. 81, no. 6, pp. 431-434, 1997.

[52] M. Abbas, L. D. Bobo, Y.-H. Hsieh et al., "Human leukocyte antigen (HLA)-B, DRB1, and DQB1 allotypes associated with disease and protection of trachoma endemic villagers," Investigative Ophthalmology and Visual Science, vol. 50, no. 4, pp. 1734-1738, 2009.
[53] C. H. Roberts, S. Molina, P. Makalo et al., "Conjunctival scarring in trachoma is associated with the HLA-C Ligand of KIR and is exacerbated by heterozygosity at KIR2DL2/KIR2DL3," PLoS Neglected Tropical Diseases, vol. 8, no. 3, Article ID e2744, 2014.

[54] C. C. Winter, J. E. Gumperz, P. Parham, E. O. Long, and N. Wagtmann, "Direct binding and functional transfer of NK cell inhibitory receptors reveal novel patterns of HLA-C allotype recognition," The Journal of Immunology, vol. 161, no. 2, pp. 571577, 1998.

[55] E. Ciccone, D. Pende, M. Vitale et al., "Self class I molecules protect normal cells from lysis mediated by autologous natural killer cells," European Journal of Immunology, vol. 24, no. 4, pp. 1003-1006, 1994.

[56] M. Colonna, E. G. Brooks, M. Falco, G. B. Ferrara, and J. L. Strominger, "Generation of allospecffic natural killer cells by stimulation across a polymorphism of HLA-C," Science, vol. 260, no. 5111, pp. 1121-1124, 1993.

[57] M. Colonna, G. Borsellino, M. Falco, G. B. Ferrara, and J. L. Strominger, "HLA-C is the inhibitory ligand that determines dominant resistance to lysis by NK1- and NK2-specific natural killer cells," Proceedings of the National Academy of Sciences of the United States of America, vol. 90, no. 24, pp. 12000-12004, 1993.

[58] R. Biassoni, C. Cantoni, M. Falco et al., "The human leukocyte antigen (HLA)-C-specific 'activatory' or 'inhibitory' natural killer cell receptors display highly homologous extracellular domains but differ in their transmembrane and intracytoplasmic portions," The Journal of Experimental Medicine, vol. 183, no. 2, pp. 645-650, 1996.

[59] E. O. Long, M. Colonna, and L. L. Lanier, "Inhibitory MHC class I receptors on NK and T cells: a standard nomenclature," Immunology Today, vol. 17, no. 2, article 100, 1996.

[60] M. Colonna and J. Samaridis, "Cloning of immunoglobulinsuperfamily members associated with HLA-C and HLA-B recognition by human natural killer cells," Science, vol. 268, no. 5209, pp. 405-408, 1995.

[61] S. Kim, J. Poursine-Laurent, S. M. Truscott et al., "Licensing of natural killer cells by host major histocompatibility complex class I molecules," Nature, vol. 436, no. 7051, pp. 709-713, 2005.

[62] A. Moretta, C. Bottino, D. Pende et al., "Identification of four subsets of human CD3-CD16+ natural killer (NK) cells by the expression of clonally distributed functional surface molecules: correlation between subset assignment of NK clones and ability to mediate specific alloantigen recognition," Journal of Experimental Medicine, vol. 172, no. 6, pp. 1589-1598, 1990.

[63] A. Moretta, G. Tambussi, C. Bottino et al., "A novel surface antigen expressed by a subset of human $\mathrm{CD}^{-} \mathrm{CD}^{-} 6^{+}$natural killer cells. Role in cell activation and regulation of cytolytic function," The Journal of Experimental Medicine, vol. 171, no. 3, pp. 695-714, 1990.

[64] B. Huard and L. Karlsson, "A subpopulation of $\mathrm{CD}^{+} \mathrm{T}$ cells specific for melanocyte differentiation antigens expresses killer inhibitory receptors (KIR) in healthy donors: evidence for a role of KIR in the control of peripheral tolerance," European Journal of Immunology, vol. 30, no. 6, pp. 1665-1675, 2000.

[65] S. Ferrini, A. Cambiaggi, R. Meazza et al., "T cell clones expressing the natural killer cell-related p58 receptor molecule display heterogeneity in phenotypic properties and p58 function," European Journal of Immunology, vol. 24, no. 10, pp. 22942298, 1994. 
[66] N.-K. S. Al Basatena, A. MacNamara, A. M. Vine et al., "KIR2DL2 enhances protective and detrimental HLA class Imediated immunity in chronic viral infection," PLoS Pathogens, vol. 7, no. 10, Article ID e1002270, 2011.

[67] W. K. Chan, P. Rujkijyanont, G. Neale et al., "Multiplex and genome-wide analyses reveal distinctive properties of $\mathrm{KIR}^{+}$and CD56 ${ }^{+}$T cells in human blood," The Journal of Immunology, vol. 191, no. 4, pp. 1625-1636, 2013.

[68] D. J. Conway, M. J. Holland, R. L. Bailey et al., "Scarring trachoma is associated with polymorphism in the tumor necrosis factor alpha (TNF- $\alpha$ ) gene promoter and with elevated TNF- $\alpha$ levels in tear fluid," Infection and Immunity, vol. 65, no. 3, pp. 1003-1006, 1997.

[69] A. Natividad, N. Hanchard, M. J. Holland et al., "Genetic variation at the TNF locus and the risk of severe sequelae of ocular Chlamydia trachomatis infection in Gambians," Genes \& Immunity, vol. 8, no. 4, pp. 288-295, 2007.

[70] B. Atik, T. A. Skwor, R. P. Kandel et al., "Identification of novel single nucleotide polymorphisms in inflammatory genes as risk factors associated with trachomatous trichiasis," PLoS ONE, vol. 3, no. 10, Article ID e3600, 2008.

[71] A. Natividad, J. Wilson, O. Koch et al., "Risk of trachomatous scarring and trichiasis in Gambians varies with SNP haplotypes at the interferon-gamma and interleukin-10 loci," Genes and Immunity, vol. 6, no. 4, pp. 332-340, 2005.

[72] A. Natividad, J. Hull, G. Luoni et al., "Innate immunity in ocular Chlamydia trachomatis infection: contribution of IL8 and CSF2 gene variants to risk of trachomatous scarring in Gambians," BMC Medical Genetics, vol. 10, article 138, 2009.

[73] A. Natividad, M. J. Holland, K. A. Rockett et al., "Susceptibility to sequelae of human ocular chlamydial infection associated with allelic variation in IL10 cis-regulation," Human Molecular Genetics, vol. 17, no. 2, pp. 323-329, 2008.

[74] M. Savy, B. J. Hennig, C. P. Doherty et al., "Haptoglobin and sickle cell polymorphisms and risk of active trachoma in gambian children," PLoS ONE, vol. 5, no. 6, Article ID el1075, 2010.

[75] Y.-Y. Teo, K. S. Small, and D. P. Kwiatkowski, "Methodological challenges of genome-wide association analysis in Africa," Nature Reviews Genetics, vol. 11, no. 2, pp. 149-160, 2010.

[76] M. J. Newport and C. Finan, "Genome-wide association studies and susceptibility to infectious diseases," Briefings in Functional Genomics, vol. 10, no. 2, pp. 98-107, 2011.

[77] M. Jallow, Y. Y. Teo, K. S. Small et al., "Genome-wide and fine-resolution association analysis of malaria in West Africa," Nature Genetics, vol. 41, pp. 657-665, 2009.

[78] B. Howie, C. Fuchsberger, M. Stephens, J. Marchini, and G. R. Abecasis, "Fast and accurate genotype imputation in genomewide association studies through pre-phasing," Nature Genetics, vol. 44, no. 8, pp. 955-959, 2012.

[79] SA. Morré, S. Ouburg, V.-D. Margreet, S. Ioana, and F. Fabrizio, "EpiGenChlamydia Consortium," 2015, http://www.epigenchlamydia.eu/cms/.

[80] C. H. Roberts, C. Franklin, S. Molina-Gonzalez et al., "A genome wide association scan reveals pathway-wide genomic differences between cases of scarring trachoma and controls," in Proceedings of the 13th International Symposium on Human Chlamydial Infections, J. Schachter, G. Byrne, M. A. Chernesky, and etal, Eds., pp. 501-504, Asilomar Conference Grounds, Pacific Grove, Calif, USA, June 2014.
[81] Y. Su, X. Wang, J. Enitra et al., "Host genetics and upper genital tract disease in Chlamydia muridarum infected mice: a forward genetic approach with translational implications," in Proceedings of the 13th International Symposium on Human Chlamydial Infections, J. Schachter, G. Byrne, M. A. Chernesky, and etal, Eds., pp. 261-264, Asilomar Conference Grounds, Pacific Grove, Calif, USA, June 2014.

[82] D. C. Ko, K. P. Shukla, C. Fong et al., "A genome-wide in vitro bacterial-infection screen reveals human variation in the host response associated with inflammatory disease," The American Journal of Human Genetics, vol. 85, no. 2, pp. 214-227, 2009.

[83] D. C. Ko and T. J. Urban, "Understanding human variation in infectious disease susceptibility through clinical and cellular GWAS," PLoS Pathogens, vol. 9, no. 8, Article ID e1003424, 2013.

[84] R. S. Stephens, S. Kalman, C. Lammel et al., "Genome sequence of an obligate intracellular pathogen of humans: Chlamydia trachomatis," Science, vol. 282, no. 5389, pp. 754-759, 1998.

[85] L. Kari, W. M. Whitmire, J. H. Carlson et al., "Pathogenic diversity among Chlamydia trachomatis ocular strains in nonhuman primates is affected by subtle genomic variations," Journal of Infectious Diseases, vol. 197, no. 3, pp. 449-456, 2008.

[86] H. M. B. Seth-Smith, S. R. Harris, K. Persson et al., "Coevolution of genomes and plasmids within Chlamydia trachomatis and the emergence in Sweden of a new variant strain," BMC Genomics, vol. 10, article 239, 2009.

[87] S. Kalman, W. Mitchell, R. Marathe et al., "Comparative genomes of Chlamydia pneumoniae and C. trachomatis," Nature Genetics, vol. 21, no. 4, pp. 385-389, 1999.

[88] T. D. Read, R. C. Brunham, C. Shen et al., "Genome sequences of Chlamydia trachomatis MoPn and Chlamydia pneumoniae AR39," Nucleic Acids Research, vol. 28, no. 6, pp. 1397-1406, 2000.

[89] M. Shirai, H. Hirakawa, M. Kimoto et al., "Comparison of whole genome sequences of Chlamydia pneumoniae J138 from Japan and CWL029 from USA," Nucleic Acids Research, vol. 28, no. 12, pp. 2311-2314, 2000.

[90] T. D. Read, G. S. A. Myers, R. C. Brunham et al., "Genome sequence of Chlamydophila caviae (Chlamydia psittaci GPIC): examining the role of niche-specific genes in the evolution of the Chlamydiaceae," Nucleic Acids Research, vol. 31, no. 8, pp. 2134-2147, 2003.

[91] S. R. Harris, I. N. Clarke, H. M. B. Seth-Smith et al., "Wholegenome analysis of diverse Chlamydia trachomatis strains identifies phylogenetic relationships masked by current clinical typing," Nature Genetics, vol. 44, no. 4, pp. 413-419, 2012.

[92] J. P. Gomes, W. J. Bruno, A. Nunes et al., "Evolution of Chlamydia trachomatis diversity occurs by widespread interstrain recombination involving hotspots," Genome Research, vol. 17, no. 1, pp. 50-60, 2007.

[93] B. M. Jeffrey, R. J. Suchland, K. L. Quinn, J. R. Davidson, W. E. Stamm, and D. D. Rockey, "Genome sequencing of recent clinical Chlamydia trachomatis strains identifies loci associated with tissue tropism and regions of apparent recombination," Infection and Immunity, vol. 78, no. 6, pp. 2544-2553, 2010.

[94] Y. Wang, S. Kahane, L. T. Cutcliffe, R. J. Skilton, P. R. Lambden, and I. N. Clarke, "Development of a transformation system for chlamydia trachomatis: restoration of glycogen biosynthesis by acquisition of a plasmid shuttle vector," PLoS Pathogens, vol. 7, no. 9, Article ID e1002258, 2011. 
[95] Y. Wang, S. Kahane, L. T. Cutcliffe et al., "Genetic transformation of a clinical (genital tract), plasmid-free isolate of Chlamydia trachomatis: engineering the plasmid as a cloning vector," PLoS ONE, vol. 8, no. 3, Article ID e59195, 2013.

[96] Y. Wang, L. T. Cutcliffe, R. J. Skilton, K. Persson, C. Bjartling, and I. N. Clarke, "Transformation of a plasmid-free, genital tract isolate of Chlamydia trachomatis with a plasmid vector carrying a deletion in CDS6 revealed that this gene regulates inclusion phenotype," Pathogens and Disease, vol. 67, no. 2, pp. 100-103, 2013.

[97] L. Song, J. H. Carlson, W. M. Whitmire et al., "Chlamydia trachomatis plasmid-encoded pgp4 is a transcriptional regulator of virulence-associated genes," Infection and Immunity, vol. 81, no. 3, pp. 636-644, 2013.

[98] L. Kari, M. M. Goheen, L. B. Randall et al., "Generation of targeted Chlamydia trachomatis null mutants," Proceedings of the National Academy of Sciences of the United States of America, vol. 108, no. 17, pp. 7189-7193, 2011.

[99] A. Omsland, J. Sager, V. Nair, D. E. Sturdevant, and T. Hackstadt, "Developmental stage-specific metabolic and transcriptional activity of Chlamydia trachomatis in an axenic medium," Proceedings of the National Academy of Sciences of the United States of America, vol. 109, no. 48, pp. 19781-19785, 2012.

[100] H. M. B. Seth-Smith, S. R. Harris, R. J. Skilton et al., "Wholegenome sequences of Chlamydia trachomatis directly from clinical samples without culture," Genome Research, vol. 23, no. 5, pp. 855-866, 2013.

[101] M. T. Christiansen, A. C. Brown, S. Kundu et al., "Wholegenome enrichment and sequencing of Chlamydia trachomatis directly from clinical samples," BMC Infectious Diseases, vol. 14, article 591, 2014.

[102] V. Borges, R. Ferreira, A. Nunes et al., "Effect of long-term laboratory propagation on Chlamydia trachomatis genome dynamics," Infection, Genetics and Evolution, vol. 17, pp. 23-32, 2013.

[103] P. M. Bavoil, G. Myers, B. Ma et al., "Eco-pathogenomics of chlamydial reproductive tract infection (EPCRTI)," in Proceedings of the 13th International Symposium on Human Chlamydial Infections, J. Schachter, G. Byrne, M. A. Chernesky et al., Eds., pp. 63-66, Asilomar Conference Grounds, Pacific Grove, Calif, USA, June 2014.

[104] C. Bonner, H. D. Caldwell, J. H. Carlson et al., "Chlamydia trachomatis virulence factor CT135 is stable in vivo but highly polymorphic in vitro," Pathogens and Disease, vol. 73, Article ID ftv043, 2015.

[105] S. D. Tyler, G. A. Peters, C. Grose et al., "Genomic cartography of varicella-zoster virus: a complete genome-based analysis of strain variability with implications for attenuation and phenotypic differences," Virology, vol. 359, no. 2, pp. 447-458, 2007.

[106] D. J. Dargan, E. Douglas, C. Cunningham et al., "Sequential mutations associated with adaptation of human cytomegalovirus to growth in cell culture," Journal of General Virology, vol. 91, pp. 1535-1546, 2010.

[107] N. L. Bachmann, M. J. Sullivan, M. Jelocnik, G. S. A. Myers, P. Timms, and A. Polkinghorne, "Culture-independent genome sequencing of clinical samples reveals an unexpected heterogeneity of infections by Chlamydia pecorum," Journal of Clinical Microbiology, vol. 53, no. 5, pp. 1573-1581, 2015.
[108] D. Longbottom, M. Russell, S. M. Dunbar, G. E. Jones, and A. J. Herring, "Molecular cloning and characterization of the genes coding for the highly immunogenic cluster of 90-kilodalton envelope proteins from the Chlamydia psittaci subtype that causes abortion in sheep," Infection \& Immunity, vol. 66, no. 4, pp. 1317-1324, 1998.

[109] D. R. Stothard, G. A. Toth, and B. E. Batteiger, "Polymorphic membrane protein $\mathrm{H}$ has evolved in parallel with the three disease-causing groups of Chlamydia trachomatis," Infection and Immunity, vol. 71, no. 3, pp. 1200-1208, 2003.

[110] J. P. Gomes, A. Nunes, W. J. Bruno, M. J. Borrego, C. Florindo, and D. Dean, "Polymorphisms in the nine polymorphic membrane proteins of Chlamydia trachomatis across all serovars: evidence for serovar da recombination and correlation with tissue tropism," Journal of Bacteriology, vol. 188, no. 1, pp. 275286, 2006.

[111] D. D. Rockey, R. A. Heinzen, and T. Hackstadt, "Cloning and characterization of a Chlamydia psittaci gene coding for a protein localized in the inclusion membrane of infected cells," Molecular Microbiology, vol. 15, no. 4, pp. 617-626, 1995.

[112] R.-C. Hsia, Y. Pannekoek, E. Ingerowski, and P. M. Bavoil, "Type III secretion genes identify a putative virulence locus of Chlamydia," Molecular Microbiology, vol. 25, no. 2, pp. 351-359, 1997.

[113] P. S. Hefty and R. S. Stephens, "Chlamydial type III secretion system is encoded on ten operons preceded by Sigma 70-like promoter elements," Journal of Bacteriology, vol. 189, no. 1, pp. 198-206, 2006.

[114] H. D. Caldwell, H. Wood, D. Crane et al., "Polymorphisms in Chlamydia trachomatis tryptophan synthase genes differentiate between genital and ocular isolates," The Journal of Clinical Investigation, vol. 111, no. 11, pp. 1757-1769, 2003.

[115] H. Wood, C. Fehlner-Gardner, J. Berry et al., "Regulation of tryptophan synthase gene expression in Chlamydia trachomatis," Molecular Microbiology, vol. 49, no. 5, pp. 1347-1359, 2003.

[116] J. H. Carlson, H. Wood, C. Roshick, H. D. Caldwell, and G. McClarty, "In vivo and in vitro studies of Chlamydia trachomatis TrpR:DNA interactions,” Molecular Microbiology, vol. 59, no. 6, pp. 1678-1691, 2006.

[117] C. M. O’Connell, Y. M. AbdelRahman, E. Green et al., "Tolllike receptor 2 activation by Chlamydia trachomatis is plasmid dependent, and plasmid-responsive chromosomal loci are coordinately regulated in response to glucose limitation by $C$. trachomatis but not by C. muridarum," Infection and Immunity, vol. 79, no. 3, pp. 1044-1056, 2011.

[118] T. Hackstadt, M. A. Scidmore-Carlson, E. I. Shaw, and E. R. Fischer, "The Chlamydia trachomatis IncA protein is required for homotypic vesicle fusion," Cellular Microbiology, vol. 1, no. 2, pp. 119-130, 1999.

[119] R. J. Suchland, D. D. Rockey, J. P. Bannantine, and W. E. Stamm, "Isolates of Chlamydia trachomatis that occupy nonfusogenic inclusions lack IncA, a protein localized to the inclusion membrane," Infection and Immunity, vol. 68, no. 1, pp. 360-367, 2000.

[120] D. E. Nelson, D. D. Crane, L. D. Taylor, D. W. Dorward, M. M. Goheen, and H. D. Caldwell, "Inhibition of chlamydiae by primary alcohols correlates with the strain-specific complement of plasticity zone phospholipase D genes," Infection and Immunity, vol. 74, no. 1, pp. 73-80, 2006. 
[121] L. D. Taylor, D. E. Nelson, D. W. Dorward, W. M. Whitmire, and H. D. Caldwell, "Biological characterization of Chlamydia trachomatis plasticity zone MACPF domain family protein CT153," Infection and Immunity, vol. 78, no. 6, pp. 2691-2699, 2010.

[122] D. LaVerda, L. N. Albanese, P. E. Ruther et al., "Seroreactivity to Chlamydia trachomatis Hsp10 correlates with severity of human genital tract disease," Infection \& Immunity, vol. 68, no. 1, pp. 303-309, 2000.

[123] A. Kol, A. H. Lichtman, R. W. Finberg, P. Libby, and E. A. KurtJones, "Cutting edge: heat shock protein (HSP) 60 activates the innate immune response: CD14 is an essential receptor for HSP60 activation of mononuclear cells," Journal of Immunology, vol. 164, no. 1, pp. 13-17, 2000.

[124] J. H. Carlson, S. Hughes, D. Hogan et al., "Polymorphisms in the Chlamydia trachomatis cytotoxin locus associated with ocular and genital isolates," Infection and Immunity, vol. 72, no. 12, pp. 7063-7072, 2004.

[125] J. H. Carlson, W. M. Whitmire, D. D. Crane et al., "The Chlamydia trachomatis plasmid is a transcriptional regulator of chromosomal genes and a virulence factor," Infection and Immunity, vol. 76, no. 6, pp. 2273-2283, 2008.

[126] L. C. Frazer, T. Darville, K. Chandra-Kuntal et al., "Plasmidcured Chlamydia caviae activates TLR2-dependent signaling and retains virulence in the guinea pig model of genital tract infection," PLoS ONE, vol. 7, no. 1, Article ID e30747, 2012.

[127] C. Tan, J. K. Spitznagel, H.-Z. Shou et al., "The polymorphic membrane protein gene family of the Chlamydiaciae," in Chlamydia: Genomics and Pathogenesis, P. M. Bavoil and P. B. Wyrick, Eds., pp. 195-218, Horizon Bioscience, Norfolk, UK, 2006.

[128] K. A. Swanson, L. D. Taylor, S. D. Frank et al., "Chlamydia trachomatis polymorphic membrane protein $\mathrm{D}$ is an oligomeric autotransporter with a higher-order structure," Infection and Immunity, vol. 77, no. 1, pp. 508-516, 2009.

[129] W. Wehrl, V. Brinkmann, P. R. Jungblut, T. F. Meyer, and A. J. Szczepek, "From the inside out-processing of the Chlamydial autotransporter PmpD and its role in bacterial adhesion and activation of human host cells," Molecular Microbiology, vol. 51, no. 2, pp. 319-334, 2004.

[130] R. J. Belland, M. A. Scidmore, D. D. Crane et al., "Chlamydia trachomatis cytotoxicity associated with complete and partial cytotoxin genes," Proceedings of the National Academy of Sciences of the United States of America, vol. 98, no. 24, pp. 1398413989, 2001.

[131] I. Tietzel, C. El-Haibi, and R. A. Carabeo, "Human guanylate binding proteins potentiate the anti-chlamydia effects of interferon-gamma," PLoS ONE, vol. 4, no. 8, Article ID e6499, 2009.

[132] N. R. Thomson, M. T. G. Holden, C. Carder et al., "Chlamydia trachomatis: genome sequence analysis of lymphogranuloma venereum isolates," Genome Research, vol. 18, no. 1, pp. 161-171, 2008.

[133] B. Fan, B. van der Pol, and D. Nelson, "Do chlamydial cytotoxins mediate IFN- $\gamma$ immune evasion," in Proceedings of the European Society for Chlamydia Research, vol. 6, pp. 165-171, 2008.

[134] M. Sait, M. Livingstone, E. M. Clark et al., "Genome sequencing and comparative analysis of three Chlamydia pecorum strains associated with different pathogenic outcomes," $B M C$ Genomics, vol. 15, article 23, 2014.
[135] A. Ciervo, F. Mancini, and A. Cassone, "Transcription, expression, localization and immunoreactivity of Chlamydophila pneumoniae Phospholipase D protein," Microbial Pathogenesis, vol. 43, no. 2, pp. 96-105, 2007.

[136] D. R. Clifton, K. A. Fields, S. S. Grieshaber et al., "A chlamydial type III translocated protein is tyrosine-phosphorylated at the site of entry and associated with recruitment of actin," Proceedings of the National Academy of Sciences of the United States of America, vol. 101, no. 27, pp. 10166-10171, 2004.

[137] W. M. Geisler, R. J. Suchland, D. D. Rockey, and W. E. Stamm, "Epidemiology and clinical manifestations of unique Chlamydia trachomatis isolates that occupy nonfusogenic inclusions," Journal of Infectious Diseases, vol. 184, no. 7, pp. 879-884, 2001.

[138] K. M. Mirrashidi, C. A. Elwell, E. Verschueren et al., "Global mapping of the inc-human interactome reveals that retromer restricts Chlamydia infection," Cell Host \& Microbe, vol. 18, no. 1, pp. 109-121, 2015.

[139] C. J. Hueck, "Type III protein secretion systems in bacterial pathogens of animals and plants," Microbiology and Molecular Biology Reviews, vol. 62, no. 2, pp. 379-433, 1998.

[140] J. J. Mecsas and E. J. Strauss, "Molecular mechanisms of bacterial virulence: type III secretion and pathogenicity islands," Emerging Infectious Diseases, vol. 2, no. 4, pp. 270-288, 1996.

[141] I. M. Sigar, J. H. Schripsema, Y. Wang et al., "Plasmid deficiency in urogenital isolates of Chlamydia trachomatis reduces infectivity and virulence in a mouse model," Pathogens and Disease, vol. 70, no. 1, pp. 61-69, 2014.

[142] M. Russell, T. Darville, K. Chandra-Kuntal, B. Smith, C. W. Andrews Jr., and C. M. O'Connell, "Infectivity acts as in vivo selection for maintenance of the chlamydial cryptic plasmid," Infection and Immunity, vol. 79, no. 1, pp. 98-107, 2011.

[143] A. R. Last, C. H. Roberts, E. Cassama et al., "Plasmid copy number and disease severity in naturally occurring ocular Chlamydia trachomatis infection," Journal of Clinical Microbiology, vol. 52, no. 1, pp. 324-327, 2014.

[144] A. J. Twigg and D. Sherratt, "Trans-complementable copynumber mutants of plasmid ColE1," Nature, vol. 283, no. 5743, pp. 216-218, 1980.

[145] N. S. Thomas, M. Lusher, C. C. Storey, and I. N. Clarke, "Plasmid diversity in Chlamydia," Microbiology, vol. 143, no. 6, pp. 18471854, 1997.

[146] Q. An, G. Radcliffe, R. Vassallo et al., "Infection with a plasmidfree variant chlamydia related to Chlamydia trachomatis identified by using multiple assays for nucleic acid detection," Journal of Clinical Microbiology, vol. 30, no. 11, pp. 2814-2821, 1992.

[147] E. M. Peterson, B. A. Markoff, J. Schachter, and L. M. de la Maza, "The 7.5-kb plasmid present in Chlamydia trachomatis is not essential for the growth of this microorganism," Plasmid, vol. 23, no. 2, pp. 144-148, 1990.

[148] S. F. Porcella, J. H. Carlson, D. E. Sturdevant et al., "Transcriptional profiling of human epithelial cells infected with plasmidbearing and plasmid-deficient Chlamydia trachomatis," Infection and Immunity, vol. 83, no. 2, pp. 534-543, 2015.

[149] M. Laabei, M. Recker, J. K. Rudkin et al., "Predicting the virulence of MRSA from its genome sequence," Genome Research, vol. 24, no. 5, pp. 839-849, 2014.

[150] T. D. Read and R. C. Massey, "Characterizing the genetic basis of bacterial phenotypes using genome-wide association studies: a new direction for bacteriology," Genome Medicine, vol. 6, no. 11, article 109, 2014. 
[151] S. K. Sheppard, X. Didelot, G. Meric et al., "Genome-wide association study identifies vitamin B5 biosynthesis as a host specificity factor in Campylobacter," Proceedings of the National Academy of Sciences of the United States of America, vol. 110, no. 29, pp. 11923-11927, 2013.

[152] M. R. Farhat, B. J. Shapiro, K. J. Kieser et al., "Genomic analysis identifies targets of convergent positive selection in drugresistant Mycobacterium tuberculosis," Nature Genetics, vol. 45, no. 10, pp. 1183-1189, 2013.

[153] M. T. Alam, R. A. Petit, E. K. Crispell et al., "Dissecting vancomycin-intermediate resistance in Staphylococcus aureus using genome-wide association," Genome Biology and Evolution, vol. 6, no. 5, pp. 1174-1185, 2014.

[154] C. Chewapreecha, P. Marttinen, N. J. Croucher et al., "Comprehensive identification of single nucleotide polymorphisms associated with beta-lactam resistance within pneumococcal mosaic genes," PLoS Genetics, vol. 10, no. 8, Article ID e1004547, 2014.

[155] V. H. Hu, P. Massae, H. A. Weiss et al., "Bacterial infection in scarring trachoma," Investigative Ophthalmology \& Visual Science, vol. 52, pp. 2181-2186, 2011.

[156] M. J. Burton, R. A. Adegbola, F. Kinteh et al., "Bacterial infection and trachoma in the Gambia: a case-control study," Investigative Ophthalmology and Visual Science, vol. 48, no. 10, pp. 44404444, 2007.

[157] V. Cevallos, J. P. Whitcher, M. Melese et al., "Association of conjunctival bacterial infection and female sex in cicatricial trachoma," Investigative Ophthalmology \& Visual Science, vol. 53, no. 9, pp. 5208-5212, 2012.

[158] M. J. Burton, V. H. Hu, P. Massae et al., "What Is causing active trachoma? The role of nonchlamydial bacterial pathogens in a low prevalence setting," Investigative Ophthalmology and Visual Science, vol. 52, no. 8, pp. 6012-6017, 2011.

[159] S. E. Burr, J. D. Hart, T. Edwards et al., "Association between ocular bacterial carriage and follicular trachoma following mass azithromycin distribution in The Gambia," PLoS Neglected Tropical Diseases, vol. 7, no. 7, Article ID e2347, 2013.

[160] M. J. Burton, R. J. C. Bowman, H. Faal et al., "Long term outcome of trichiasis surgery in the Gambia," British Journal of Ophthalmology, vol. 89, no. 5, pp. 575-579, 2005.

[161] M. J. Burton, R. L. Bailey, D. Jeffries et al., "Conjunctival expression of matrix metalloproteinase and proinflammatory cytokine genes after trichiasis surgery," Investigative Ophthalmology and Visual Science, vol. 51, no. 7, pp. 3583-3590, 2010.

[162] D. N. Frank, A. L. St Amand, R. A. Feldman, E. C. Boedeker, N. Harpaz, and N. R. Pace, "Molecular-phylogenetic characterization of microbial community imbalances in human inflammatory bowel diseases," Proceedings of the National Academy of Sciences of the United States of America, vol. 104, no. 34, pp. 13780-13785, 2007.

[163] B. Willing, J. Halfvarson, J. Dicksved et al., “Twin studies reveal specific imbalances in the mucosa-associated microbiota of patients with ileal Crohn's disease," Inflammatory Bowel Diseases, vol. 15, no. 5, pp. 653-660, 2009.

[164] A. W. Walker, J. D. Sanderson, C. Churcher et al., "Highthroughput clone library analysis of the mucosa-associated microbiota reveals dysbiosis and differences between inflamed and non-inflamed regions of the intestine in inflammatory bowel disease," BMC Microbiology, vol. 11, article 7, 2011.

[165] A. J. McDermott and G. B. Huffnagle, "The microbiome and regulation of mucosal immunity," Immunology, vol. 142, no. 1, pp. 24-31, 2014.
[166] M. Valentini, A. Piermattei, G. Di Sante, G. Migliara, G. Delogu, and F. Ria, "Immunomodulation by gut microbiota: role of Toll-like receptor expressed by T cells," Journal of Immunology Research, vol. 2014, Article ID 586939, 8 pages, 2014.

[167] M. M. Kosiewicz, A. L. Zirnheld, and P. Alard, "Gut microbiota, immunity, and disease: a complex relationship," Frontiers in Microbiology, vol. 2, article 180, 2011.

[168] N. Van Oostrum, P. De Sutter, J. Meys, and H. Verstraelen, "Risks associated with bacterial vaginosis in infertility patients: a systematic review and meta-analysis," Human Reproduction, vol. 28, no. 7, pp. 1809-1815, 2013.

[169] S. D. Spandorfer, A. Neuer, P. C. Giraldo, Z. Rosenwaks, and S. S. Witkin, "Relationship of abnormal vaginal flora, proinflammatory cytokines and idiopathic infertility in women undergoing IVF," Journal of Reproductive Medicine for the Obstetrician and Gynecologist, vol. 46, no. 9, pp. 806-810, 2001.

[170] Q. Dong, J. M. Brulc, A. Iovieno et al., "Diversity of bacteria at healthy human conjunctiva," Investigative Ophthalmology and Visual Science, vol. 52, no. 8, pp. 5408-5413, 2011.

[171] Y. Zhou, H. Gao, K. A. Mihindukulasuriya et al., "Biogeography of the ecosystems of the healthy human body," Genome Biology, vol. 14, article R1, 2013.

[172] Y. Zhou, M. J. Holland, P. Makalo et al., "The conjunctival microbiome in health and trachomatous disease: a case control study," Genome Medicine, vol. 6, article 99, 2014.

[173] R. P. Dickson, J. R. Erb-Downward, and G. B. Huffnagle, “The role of the bacterial microbiome in lung disease," Expert Review of Respiratory Medicine, vol. 7, no. 3, pp. 245-257, 2013.

[174] D.-P. Mao, Q. Zhou, C.-Y. Chen, and Z.-X. Quan, “Coverage evaluation of universal bacterial primers using the metagenomic datasets," BMC Microbiology, vol. 12, article 66, 2012.

[175] G. Dubourg, J. C. Lagier, F. Armougom et al., “The gut microbiota of a patient with resistant tuberculosis is more comprehensively studied by culturomics than by metagenomics," European Journal of Clinical Microbiology and Infectious Diseases, vol. 32, no. 5, pp. 637-645, 2013.

[176] A. A. Pezzulo, P. H. Kelly, B. S. Nassar et al., "Abundant dnase Isensitive bacterial DNA in healthy porcine lungs and its implications for the lung microbiome," Applied and Environmental Microbiology, vol. 79, no. 19, pp. 5936-5941, 2013.

[177] J.-C. Lagier, F. Armougom, M. Million et al., "Microbial culturomics: paradigm shift in the human gut microbiome study," Clinical Microbiology and Infection, vol. 18, no. 12, pp. 1185-1193, 2012.

[178] J.-C. Lagier, M. Million, P. Hugon, F. Armougom, and D. Raoult, "Human gut microbiota: repertoire and variations," Frontiers in Cellular and Infection Microbiology, vol. 2, article 136, 2012.

[179] A. Omsland, T. Hackstadt, and R. A. Heinzen, "Bringing culture to the uncultured: Coxiella burnetii and lessons for obligate intracellular bacterial pathogens," PLoS Pathogens, vol. 9, no. 9, Article ID e1003540, 2013.

[180] N. W. Palm, M. R. de Zoete, T. W. Cullen et al., "Immunoglobulin A coating identifies colitogenic bacteria in inflammatory bowel disease," Cell, vol. 158, no. 5, pp. 1000-1010, 2014.

[181] A. L. Kau, J. D. Planer, J. Liu et al., "Functional characterization of IgA-targeted bacterial taxa from undernourished Malawian children that produce diet-dependent enteropathy," Science Translational Medicine, vol. 7, no. 276, Article ID 276ra24, 2015. 
[182] H. Bierne, M. Hamon, and P. Cossart, "Epigenetics and bacterial infections," Cold Spring Harbor Perspectives in Medicine, 2012.

[183] S.-H. Shin, S.-Y. Park, J.-S. Ko, N. Kim, and G. H. Kang, "Aberrant $\mathrm{CpG}$ island hypermethylation in pediatric gastric mucosa in association with helicobacter pylori infection," Archives of Pathology \& Laboratory Medicine, vol. 135, no. 6, pp. 759-765, 2011.

[184] F.-Y. Huang, A. O.-O. Chan, A. Rashid, D. K.-H. Wong, C.H. Cho, and M.-F. Yuen, "Helicobacter pylori induces promoter methylation of $\mathrm{E}$-cadherin via interleukin- $1 \beta$ activation of nitric oxide production in gastric cancer cells," Cancer, vol. 118, no. 20, pp. 4969-4980, 2012.

[185] J. Kleinnijenhuis, J. Quintin, F. Preijers et al., "Bacille CalmetteGuérin induces NOD2-dependent nonspecific protection from reinfection via epigenetic reprogramming of monocytes," Proceedings of the National Academy of Sciences of the United States of America, vol. 109, no. 43, pp. 17537-17542, 2012.

[186] M. Murata, Y. Azuma, K. Miura et al., "Chlamydial SET domain protein functions as a histone methyltransferase," Microbiology, vol. 153, no. 2, pp. 585-592, 2007.

[187] M. E. Pennini, S. Perrinet, A. Dautry-Varsat, and A. Subtil, "Histone methylation by NUE, a novel nuclear effector of the intracellular pathogen Chlamydia trachomatis," PLoS Pathogens, vol. 6, no. 7, Article ID e1000995, pp. 1-12, 2010.

[188] M. S. Humphrys, T. Creasy, Y. Sun et al., "Simultaneous transcriptional profiling of bacteria and their host cells," PLoS ONE, vol. 8, no. 12, Article ID e80597, 2013.

[189] P. Kapranov, J. Cheng, S. Dike et al., "RNA maps reveal new RNA classes and a possible function for pervasive transcription," Science, vol. 316, no. 5830, pp. 1484-1488, 2007.

[190] R. C. Friedman, K. K.-H. Farh, C. B. Burge, and D. P. Bartel, "Most mammalian mRNAs are conserved targets of microRNAs," Genome Research, vol. 19, no. 1, pp. 92-105, 2009.

[191] J. Martinez, A. Patkaniowska, H. Urlaub, R. Lührmann, and T. Tuschl, "Single-stranded antisense siRNAs guide target RNA cleavage in RNAi," Cell, vol. 110, no. 5, pp. 563-574, 2002.

[192] C. E. Vejnar and E. M. Zdobnov, “11673," Nucleic Acids Research, vol. 40, no. 22, pp. 11673-11683, 2012.

[193] D. P. Bartel, "MicroRNAs: genomics, biogenesis, mechanism, and function," Cell, vol. 116, no. 2, pp. 281-297, 2004.

[194] V. Ambros, “The functions of animal microRNAs," Nature, vol. 431, no. 7006, pp. 350-355, 2004.

[195] S. Memczak, M. Jens, A. Elefsinioti et al., "Circular RNAs are a large class of animal RNAs with regulatory potency," Nature, vol. 495, no. 7441, pp. 333-338, 2013.

[196] T. B. Hansen, T. I. Jensen, B. H. Clausen et al., "Natural RNA circles function as efficient microRNA sponges," Nature, vol. 495, no. 7441, pp. 384-388, 2013.

[197] M. Van Kouwenhove, M. Kedde, and R. Agami, "MicroRNA regulation by RNA-binding proteins and its implications for cancer," Nature Reviews Cancer, vol. 11, no. 9, pp. 644-656, 2011.

[198] S. R. Viswanathan, G. Q. Daley, and R. I. Gregory, "Selective blockade of microRNA processing by Lin28," Science, vol. 320, no. 5872, pp. 97-100, 2008.

[199] C. Staedel and F. Darfeuille, "MicroRNAs and bacterial infection," Cellular Microbiology, vol. 15, no. 9, pp. 1496-1507, 2013.

[200] A. Eulalio, L. N. Schulte, and J. Voge, "The mammalian microRNA response to bacterial infections," RNA Biology, vol. 9, no. 6, pp. 742-750, 2012.
[201] C. Maudet, M. Mano, and A. Eulalio, "microRNAs in the interaction between host and bacterial pathogens," FEBS Letters, vol. 588, no. 22, pp. 4140-4147, 2014.

[202] L. Yeruva, G. S. Myers, N. Spencer et al., "Early microRNA expression profile as a prognostic biomarker for the development of pelvic inflammatory disease in a mouse model of chlamydial genital infection," mBio, vol. 5, no. 3, Article ID e01241-14, 2014.

[203] R. Gupta, T. Arkatkar, J.-J. Yu et al., "Chlamydia muridarum infection associated host MicroRNAs in the murine genital tract and contribution to generation of host immune response," The American Journal of Reproductive Immunology, vol. 73, no. 2, pp. 126-140, 2015.

[204] R. L. Rossi, G. Rossetti, L. Wenandy et al., "Distinct microRNA signatures in human lymphocyte subsets and enforcement of the naive state in $\mathrm{CD}^{+} \mathrm{T}$ cells by the microRNA miR-125b," Nature Immunology, vol. 12, no. 8, pp. 796-803, 2011.

[205] J. U. Igietseme, Y. Omosun, J. Partin et al., "Prevention of chlamydia-induced infertility by inhibition of local caspase activity," The Journal of Infectious Diseases, vol. 207, no. 7, pp. 1095-1104, 2013.

[206] W. Zhang, X. Yi, S. Guo et al., "A single-nucleotide polymorphism of miR-146a and psoriasis: an association and functional study," Journal of Cellular and Molecular Medicine, vol. 18, no. 11, pp. 2225-2234, 2014.

[207] W. Wang, F. R. Stassen, H.-M. Surcel et al., "Analyses of polymorphisms in the inflammasome-associated NLRP3 and miRNA-146A genes in the susceptibility to and tubal pathology of Chlamydia trachomatis infection," Drugs of Today, vol. 45, pp. 95-103, 2009.

[208] T. Derrick, C. h. Roberts, M. Rajasekhar et al., "Conjunctival MicroRNA expression in inflammatory trachomatous scarring," PLoS Neglected Tropical Diseases, vol. 7, no. 3, p. e2117, 2013.

[209] G. Liu, A. Friggeri, Y. Yang, Y.-J. Park, Y. Tsuruta, and E. Abraham, "miR-147, a microRNA that is induced upon toll-like receptor stimulation, regulates murine macrophage inflammatory responses," Proceedings of the National Academy of Sciences of the United States of America, vol. 106, no. 37, pp. 15819-15824, 2009.

[210] T. Bertero, S. Grosso, K. Robbe-Sermesant et al., "'Seedmilarity' confers to hsa-miR-210 and hsa-miR-147b similar functional activity," PLoS ONE, vol. 7, Article ID e44919, 2012.

[211] S. Tian, S. Huang, S. Wu, W. Guo, J. Li, and X. He, "MicroRNA1285 inhibits the expression of p53 by directly targeting its $3^{\prime}$ untranslated region," Biochemical and Biophysical Research Communications, vol. 396, no. 2, pp. 435-439, 2010.

[212] H. Hidaka, N. Seki, H. Yoshino et al., "Tumor suppressive microRNA-1285 regulates novel molecular targets: aberrant expression and functional significance in renal cell carcinoma," Oncotarget, vol. 3, no. 1, pp. 44-57, 2012.

[213] B. R. Cullen, "Viruses and microRNAs: RISCy interactions with serious consequences," Genes \& Development, vol. 25, no. 18, pp. 1881-1894, 2011.

[214] W. de Vries and B. Berkhout, "RNAi suppressors encoded by pathogenic human viruses," The International Journal of Biochemistry \& Cell Biology, vol. 40, no. 10, pp. 2007-2012, 2008.

[215] M. Kumar, S. K. Sahu, R. Kumar et al., "microRNA let-7 modulates the immune response to Mycobacterium tuberculosis infection via control of A20, an inhibitor of the NF- $\kappa$ B pathway," Cell Host \& Microbe, vol. 17, no. 3, pp. 345-356, 2015. 
[216] A. H. Buck, G. Coakley, F. Simbari et al., "Exosomes secreted by nematode parasites transfer small RNAs to mammalian cells and modulate innate immunity," Nature Communications, vol. 5, article 5488, 2014.

[217] Y. Furuse, R. Finethy, H. A. Saka et al., "Search for microRNAs expressed by intracellular bacterial pathogens in infected mammalian cells," PLoS ONE, vol. 9, no. 9, Article ID e106434, 2014.

[218] Y. M. Abdelrahman, L. A. Rose, and R. J. Belland, “Developmental expression of non-coding RNAs in Chlamydia trachomatis during normal and persistent growth," Nucleic Acids Research, vol. 39, no. 5, pp. 1843-1854, 2011.

[219] M. Albrecht, C. M. Sharma, R. Reinhardt, J. Vogel, and T. Rudel, "Deep sequencing-based discovery of the Chlamydia trachomatis transcriptome," Nucleic Acids Research, vol. 38, no. 3, Article ID gkp1032, pp. 868-877, 2009.

[220] S. Ricci, R. Cevenini, E. Cosco, M. Comanducci, G. Ratti, and V. Scarlato, "Transcriptional analysis of the Chlamydia trachomatis plasmid pCT identifies temporally regulated transcripts, antisense RNA and $\sigma^{70}$-selected promoters," Molecular \& General Genetics, vol. 237, no. 3, pp. 318-326, 1993.

[221] R. Kalluri and R. A. Weinberg, "The basics of epithelialmesenchymal transition," The Journal of Clinical Investigation, vol. 119, no. 6, pp. 1420-1428, 2009.

[222] M. Zeisberg and E. G. Neilson, "Biomarkers for epithelialmesenchymal transitions," Journal of Clinical Investigation, vol. 119, no. 6, pp. 1429-1437, 2009.

[223] E. M. Zeisberg, O. Tarnavski, M. Zeisberg et al., "Endothelialto-mesenchymal transition contributes to cardiac fibrosis," Nature Medicine, vol. 13, no. 8, pp. 952-961, 2007.

[224] H. Okada, F. Strutz, T. M. Danoff, R. Kalluri, and E. G. Neilson, "Possible mechanisms of renal fibrosis," Contributions to Nephrology, vol. 118, pp. 147-154, 1996.

[225] M. Iwano, D. Plieth, T. M. Danoff, C. Xue, H. Okada, and E. G. Neilson, "Evidence that fibroblasts derive from epithelium during tissue fibrosis," The Journal of Clinical Investigation, vol. 110, no. 3, pp. 341-350, 2002.

[226] M. Chilosi, V. Poletti, A. Zamò et al., "Aberrant Wnt/betacatenin pathway activation in idiopathic pulmonary fibrosis," American Journal of Pathology, vol. 162, no. 5, pp. 1495-1502, 2003.

[227] M. Zeisberg, C. Yang, M. Martino et al., "Fibroblasts derive from hepatocytes in liver fibrosis via epithelial to mesenchymal transition," Journal of Biological Chemistry, vol. 282, no. 32, pp. 23337-23347, 2007.

[228] C. Yan, W. A. Grimm, W. L. Garner et al., "Epithelial to mesenchymal transition in human skin wound healing is induced by tumor necrosis factor-alpha through bone morphogenic protein-2," American Journal of Pathology, vol. 176, no. 5, pp. 2247-2258, 2010.

[229] J. P. Thiery, H. Acloque, R. Y. J. Huang, and M. A. Nieto, "Epithelial-mesenchymal transitions in development and disease," Cell, vol. 139, no. 5, pp. 871-890, 2009.

[230] A.-P. Morel, M. Lièvre, C. Thomas, G. Hinkal, S. Ansieau, and A. Puisieux, "Generation of breast cancer stem cells through epithelial-mesenchymal transition," PLoS ONE, vol. 3, no. 8, Article ID e2888, 2008.

[231] U. Wellner, J. Schubert, U. C. Burk et al., "The EMT-activator ZEB1 promotes tumorigenicity by repressing stemnessinhibiting microRNAs," Nature Cell Biology, vol. 11, no. 12, pp. 1487-1495, 2009.
[232] S. A. Mani, W. Guo, M.-J. Liao et al., "The epithelial-mesenchymal transition generates cells with properties of stem cells," Cell, vol. 133, no. 4, pp. 704-715, 2008.

[233] O. G. McDonald, H. Wu, W. Timp, A. Doi, and A. P. Feinberg, "Genome-scale epigenetic reprogramming during epithelialto-mesenchymal transition," Nature Structural \& Molecular Biology, vol. 18, no. 8, pp. 867-874, 2011.

[234] M. Lombaerts, T. van Wezel, K. Philippo et al., "E-cadherin transcriptional downregulation by promoter methylation but not mutation is related to epithelial-to-mesenchymal transition in breast cancer cell lines," British Journal of Cancer, vol. 94, no. 5, pp. 661-671, 2006.

[235] N. Dumont, M. B. Wilson, Y. G. Crawford, P. A. Reynolds, M. Sigaroudinia, and T. D. Tlsty, "Sustained induction of epithelial to mesenchymal transition activates DNA methylation of genes silenced in basal-like breast cancers," Proceedings of the National Academy of Sciences of the United States of America, vol. 105, no. 39, pp. 14867-14872, 2008.

[236] S.-O. Lim, J.-M. Gu, M. S. Kim et al., "Epigenetic changes induced by reactive oxygen species in hepatocellular carcinoma: methylation of the E-cadherin promoter," Gastroenterology, vol. 135 , no. 6, pp. 2128-2140.e8, 2008.

[237] H. Peinado, E. Ballestar, M. Esteller, and A. Cano, "Snail mediates E-cadherin repression by the recruitment of the Sin3A/ histone deacetylase 1 (HDAC1)/HDAC2 complex," Molecular and Cellular Biology, vol. 24, no. 1, pp. 306-319, 2004.

[238] S. K. Bose, K. Meyer, A. M. Di Bisceglie, R. B. Ray, and R. Ray, "Hepatitis $\mathrm{C}$ virus induces epithelial-mesenchymal transition in primary human hepatocytes," Journal of Virology, vol. 86, no. 24, pp. 13621-13628, 2012.

[239] L. Zhao, R. Yang, L. Cheng, M. Wang, Y. Jiang, and S. Wang, "LPS-induced epithelial-mesenchymal transition of intrahepatic biliary epithelial cells," Journal of Surgical Research, vol. 171, no. 2, pp. 819-825, 2011.

[240] V. Pozharskaya, E. Torres-González, M. Rojas et al., "Twist: a regulator of epithelial-mesenchymal transition in lung fibrosis," PLoS ONE, vol. 4, no. 10, Article ID e7559, 2009.

[241] G. Cane, A. Ginouvès, S. Marchetti et al., "HIF-1alpha mediates the induction of IL-8 and VEGF expression on infection with Afa/Dr diffusely adhering E. coli and promotes EMT-like behaviour," Cellular Microbiology, vol. 12, no. 5, pp. 640-653, 2010.

[242] E. Papini, B. Satin, N. Norais et al., "Selective increase of the permeability of polarized epithelial cell monolayers by Helicobacter pylori vacuolating toxin," The Journal of Clinical Investigation, vol. 102, no. 4, pp. 813-820, 1998.

[243] M. R. Amieva, R. Vogetmann, A. Covacci, L. S. Tompkins, W. J. Nelson, and S. Falkow, "Disruption of the epithelial apicaljunctional complex by Helicobacter pylori CagA," Science, vol. 300, no. 5624, pp. 1430-1434, 2003.

[244] N. Murata-Kamiya, Y. Kurashima, Y. Teishikata et al., "Helicobacter pylori CagA interacts with E-cadherin and deregulates the $\beta$-catenin signal that promotes intestinal transdifferentiation in gastric epithelial cells," Oncogene, vol. 26, no. 32, pp. 4617-4626, 2007.

[245] F. Yin, A. M. Grabowska, P. A. Clarke et al., "Helicobacter pylori potentiates epithelial:mesenchymal transition in gastric cancer: links to soluble HB-EGF, gastrin and matrix metalloproteinase7," Gut, vol. 59, no. 8, pp. 1037-1045, 2010. 
[246] J. Baud, C. Varon, S. Chabas, L. Chambonnier, F. Darfeuille, and C. Staedel, "Helicobacter pylori initiates a mesenchymal transition through ZEB1 in gastric epithelial cells," PLoS ONE, vol. 8, no. 4, Article ID e60315, 2013.

[247] M. Kessler, J. Zielecki, O. Thieck, H.-J. Mollenkopf, C. Fotopoulou, and T. F. Meyer, "Chlamydia trachomatis disturbs epithelial tissue homeostasis in fallopian tubes via paracrine Wnt signaling," American Journal of Pathology, vol. 180, no. 1, pp. 186-198, 2012.

[248] W. C. Prozialeck, M. J. Fay, P. C. Lamar, C. A. Pearson, I. Sigar, and K. H. Ramsey, "Chlamydia trachomatis disrupts N-cadherin-dependent cell-cell junctions and sequesters beta-catenin in human cervical epithelial cells," Infection and Immunity, vol. 70, no. 5, pp. 2605-2613, 2002.

[249] J. Sun, J. Kintner, and R. V. Schoborg, "The host adherens junction molecule nectin-1 is downregulated in Chlamydia trachomatis-infected genital epithelial cells," Microbiology, vol. 154, no. 5, pp. 1290-1299, 2008.

[250] M. J. Holland, D. Jeffries, M. Pattison et al., "Pathway-focused arrays reveal increased matrix metalloproteinase-7 (Matrilysin) transcription in trachomatous trichiasis," Investigative Ophthalmology and Visual Science, vol. 51, no. 8, pp. 3893-3902, 2010.

[251] H.-C. Chen, Y.-T. Zhu, S.-Y. Chen, and S. C. G. Tseng, "Wnt signaling induces epithelial-mesenchymal transition with proliferation in ARPE-19 cells upon loss of contact inhibition," Laboratory Investigation, vol. 92, no. 5, pp. 676-687, 2012.

[252] D. A. Cusanovich, C. Billstrand, X. Zhou et al., "The combination of a genome-wide association study of lymphocyte count and analysis of gene expression data reveals novel asthma candidate genes," Human Molecular Genetics, vol. 21, no. 9, pp. 2111-2123, 2012.

[253] P. Jia and Z. Zhao, "Network-assisted analysis to prioritize GWAS results: principles, methods and perspectives," Human Genetics, vol. 133, no. 2, pp. 125-138, 2014.

[254] P. Holmans, E. K. Green, J. S. Pahwa et al., "Gene ontology analysis of GWA study data sets provides insights into the biology of bipolar disorder," The American Journal of Human Genetics, vol. 85, no. 1, pp. 13-24, 2009.

[255] R. Braun and K. Buetow, "Pathways of distinction analysis: a new technique for multi-SNP analysis of GWAS data," PLoS Genetics, vol. 7, no. 6, Article ID e1002101, 2011.

[256] C. S. Greene, N. M. Penrod, J. Kiralis, and J. H. Moore, "Spatially uniform reliefF (SURF) for computationally-efficient filtering of gene-gene interactions," BioData Mining, vol. 2, article 5, 2009.

[257] M. D. Ritchie, L. W. Hahn, N. Roodi et al., "Multifactor-dimensionality reduction reveals high-order interactions among estrogen-metabolism genes in sporadic breast cancer," The American Journal of Human Genetics, vol. 69, no. 1, pp. 138-147, 2001.

[258] P. Jia and Z. Zhao, "Searching joint association signals in CATIE schizophrenia genome-wide association studies through a refined integrative network approach," BMC Genomics, vol. 13, supplement 6, article S15, 2012.

[259] S. Purcell, B. Neale, K. Todd-Brown et al., "PLINK: a tool set for whole-genome association and population-based linkage analyses," The American Journal of Human Genetics, vol. 81, no. 3, pp. 559-575, 2007.

[260] L. S. Chen, C. M. Hutter, J. D. Potter et al., "Insights into colon cancer etiology via a regularized approach to gene set analysis of GWAS data," The American Journal of Human Genetics, vol. 86, no. 6, pp. 860-871, 2010.
[261] D. Knights, M. S. Silverberg, R. K. Weersma et al., “Complex host genetics influence the microbiome in inflammatory bowel disease," Genome Medicine, vol. 6, article 107, 2014.

[262] B. P. Fairfax, S. Makino, J. Radhakrishnan et al., "Genetics of gene expression in primary immune cells identifies cell typespecific master regulators and roles of HLA alleles," Nature Genetics, vol. 44, no. 5, pp. 502-510, 2012.

[263] D. Wong, W. Lee, P. Humburg et al., "Genomic mapping of the MHC transactivator CIITA using an integrated ChIP-seq and genetical genomics approach," Genome Biology, vol. 15, no. 10, p. 494, 2014.

[264] D. E. Sturdevant, K. Virtaneva, C. Martens et al., "Hostmicrobe interaction systems biology: lifecycle transcriptomics and comparative genomics," Future Microbiology, vol. 5, no. 2, pp. 205-219, 2010. 


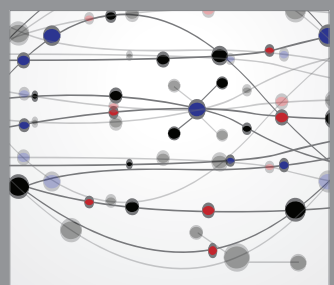

The Scientific World Journal
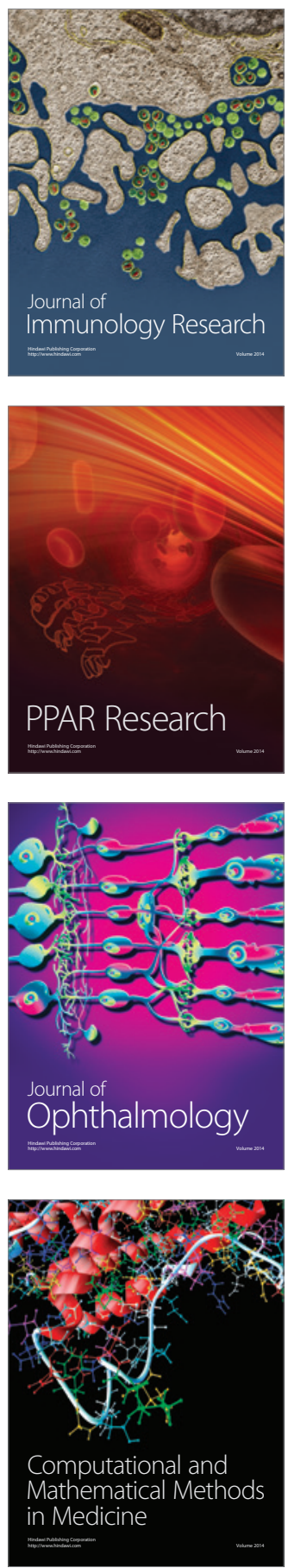

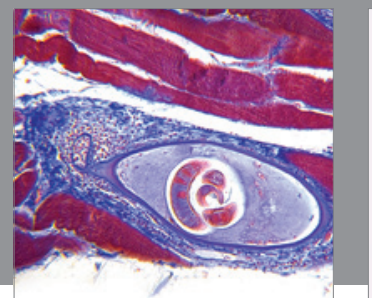

Gastroenterology

Research and Practice


\section{Hindawi}

Submit your manuscripts at

http://www.hindawi.com
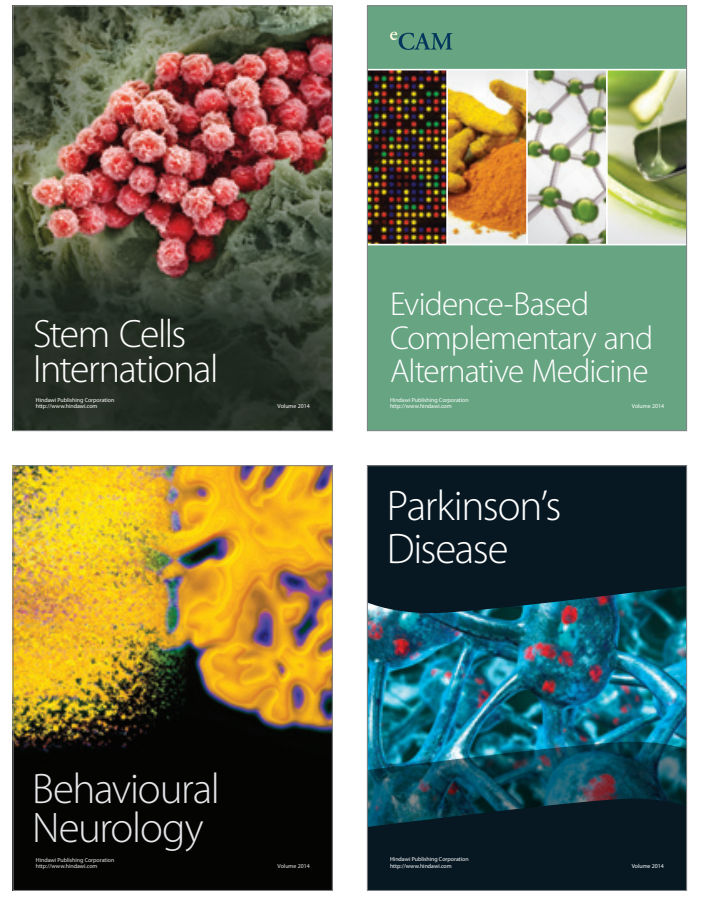
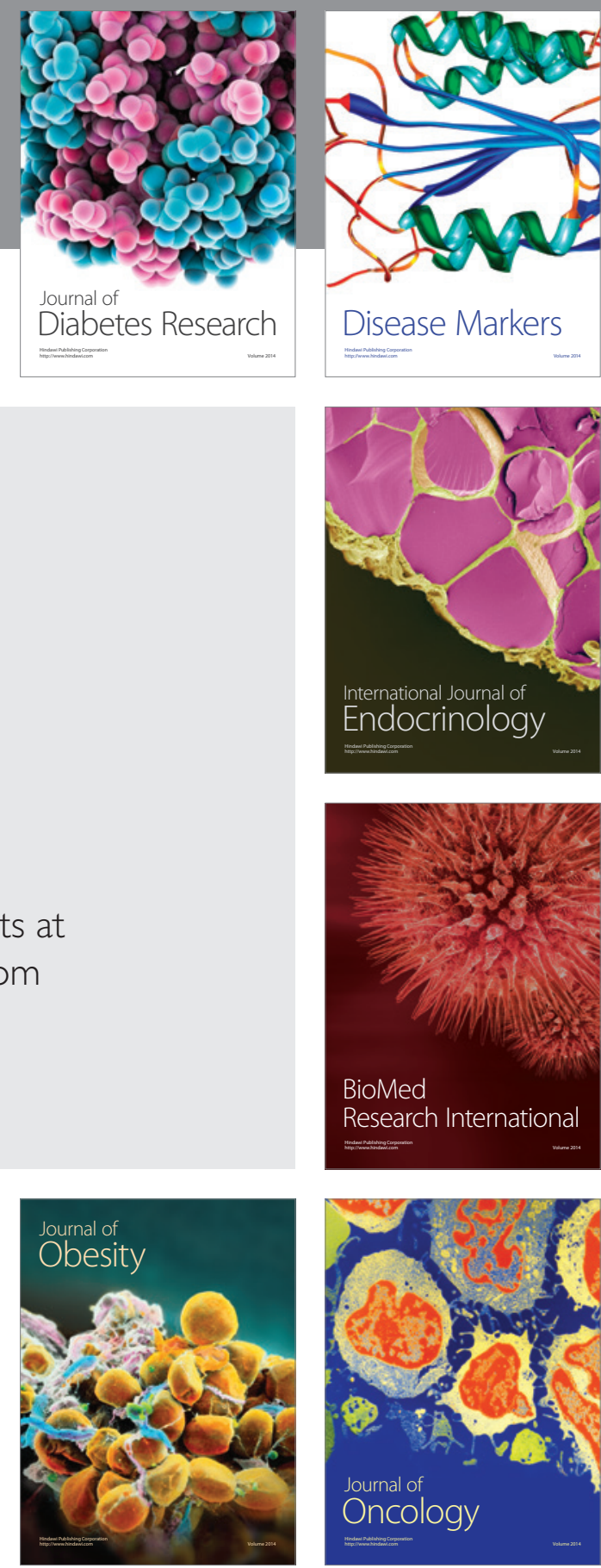

Disease Markers
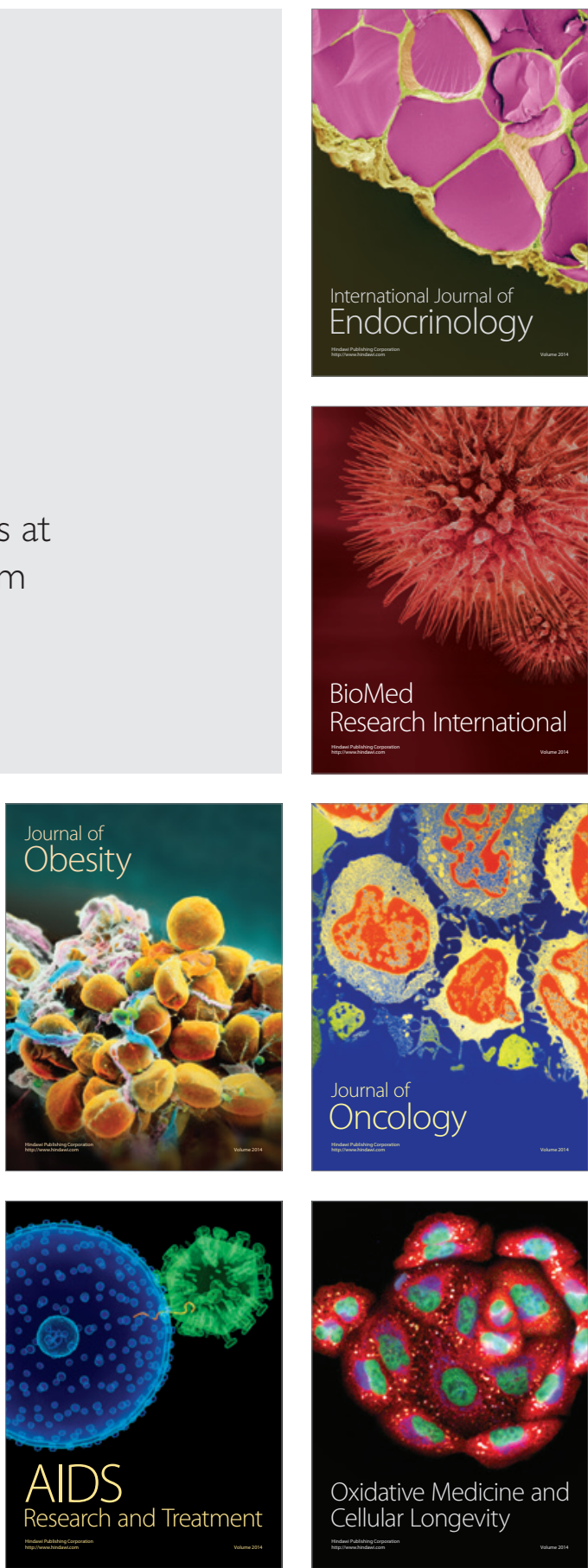